\title{
Publicaciones del padre Francisco Javier Ibisate
}

REVISTA ECA

\begin{tabular}{|c|c|c|c|c|}
\hline Año & FECHA & No. & $\begin{array}{c}\text { Nombre del artículo publicado en } \\
\text { revista ECA }\end{array}$ & Págs. \\
\hline 1969 & $\begin{array}{c}\text { Noviembre-Diciembre } \\
1969\end{array}$ & $254-255$ & $\begin{array}{l}\text { La planificación del desarrollo social y } \\
\text { económico }\end{array}$ & $475-496$ \\
\hline 1976 & $\begin{array}{c}\text { Septiembre-Octubre } \\
1976\end{array}$ & $335-336$ & $\begin{array}{l}\text { Propiedad, productividad y planificación } \\
\text { ¿para quién? }\end{array}$ & $497-510$ \\
\hline 1979 & Julio-Agosto 1979 & $369-370$ & $\begin{array}{l}\text { ¿Es capitalista el "capitalismo salvado- } \\
\text { reño"? }\end{array}$ & $535-544$ \\
\hline 1980 & Enero-Febrero 1980 & $375-376$ & $\begin{array}{l}\text { La nacionalización de la banca ¿Para qué } \\
\text { y para quiénes? (Comentario) }\end{array}$ & $91-94$ \\
\hline 1980 & Julio-Agosto 1980 & $381-382$ & $\begin{array}{l}\text { Polonia: Huelgas económicas, causas } \\
\text { políticas }\end{array}$ & $707-714$ \\
\hline 1981 & Jun-81 & 392 & $\begin{array}{l}\text { ¿Expira el Tratado General de Integración } \\
\text { Económica? (Comentario) }\end{array}$ & $555-558$ \\
\hline 1981 & Jul-81 & 393 & La lección de Polonia (Comentario) & $698-700$ \\
\hline 1981 & Ago-81 & 394 & $\begin{array}{l}\text { El Simposio Nacional para el análisis y } \\
\text { perspectivas del sector productivo de El } \\
\text { Salvador, Julio de } 1981 \text { (Comentario) }\end{array}$ & $792-794$ \\
\hline 1981 & Sep-81 & 395 & $\begin{array}{l}\text { La Segunda convocatoria de la Unidad } \\
\text { Productiva ampliada (Comentario) }\end{array}$ & 896-898 \\
\hline 1981 & $\begin{array}{l}\text { Octubre-Noviembre } \\
1981\end{array}$ & $396-397$ & $\begin{array}{l}\text { Cancún: la reunión de los veintiuno más } \\
\text { uno (Comentario) }\end{array}$ & $\begin{array}{l}1013- \\
1018\end{array}$ \\
\hline 1982 & $\begin{array}{c}\text { Septiembre-Octubre } \\
1982\end{array}$ & $407-408$ & $\begin{array}{l}\text { La crisis de } 1970-1980 \ldots \text { ¿Es realmente } \\
\text { una crisis? }\end{array}$ & $897-910$ \\
\hline
\end{tabular}




\begin{tabular}{|c|c|c|c|c|}
\hline Año & FECHA & No. & $\begin{array}{c}\text { Nombre del artículo publicado en } \\
\text { revista ECA }\end{array}$ & Págs. \\
\hline 1983 & Feb-83 & 412 & $\begin{array}{l}\text { ¿Crisis mundial financiera por endeuda- } \\
\text { miento del tercer mundo? (Comentario) }\end{array}$ & 180-184 \\
\hline 1983 & Mayo-Junio 1983 & $415-416$ & $\begin{array}{l}\text { La empresa privada frente a los tres pro- } \\
\text { blemas nacionales: El plan norteamerica- } \\
\text { no, las elecciones y la guerra }\end{array}$ & 493-500 \\
\hline 1985 & Mayo-Junio 1985 & $439-440$ & $\begin{array}{l}\text { Características y resultados de la gestión } \\
\text { económica }\end{array}$ & $357-379$ \\
\hline 1986 & Abr-86 & 450 & $\begin{array}{l}\text { Un Programa de Estabilización y Reactiva- } \\
\text { ción Económica }\end{array}$ & $275-290$ \\
\hline 1986 & $\begin{array}{l}\text { Noviembre-Diciembre } \\
1986\end{array}$ & $457-458$ & $\begin{array}{l}\text { El sector empresarial en la encrucijada. } \\
\text { Un modelo de reconstrucción }\end{array}$ & $965-981$ \\
\hline 1988 & May-88 & 475 & $\begin{array}{l}\text { "Perestroika:" Nuevas ideas para mi país } \\
\text { y el mundo }\end{array}$ & $349-376$ \\
\hline 1989 & Agosto-Septiembre 1989 & $490-491$ & $\begin{array}{l}\text { A los cien días de gobierno, ¿hacia dónde } \\
\text { vamos? }\end{array}$ & $647-668$ \\
\hline 1990 & Abril-Mayo 1990 & 498-499 & $\begin{array}{l}\text { La post-perestroika en el bloque socialista } \\
\text { y su repercusión en nuestro tercer mundo }\end{array}$ & 291-314 \\
\hline 1990 & Oct-90 & 504 & $\begin{array}{l}\text { Mijail Gorbachov: Premio Nobel de la } \\
\text { Paz } 1990\end{array}$ & $907-911$ \\
\hline 1991 & Julio-Agosto 1991 & $513-514$ & $\begin{array}{l}\text { Los "socialismos reales" hacen su propia } \\
\text { autocrítica y redescubren su historia }\end{array}$ & $675-710$ \\
\hline 1992 & Mar-92 & 521 & La política de reconstrucción nacional & $245-259$ \\
\hline 1993 & Enero-Febrero 1993 & $531-532$ & $\begin{array}{l}\text { Mensaje de Juan Pablo II para la Jornada } \\
\text { Mundial de la Paz "Si quieres la paz, sal al } \\
\text { encuentro del pobre" (Comentario) }\end{array}$ & $96-99$ \\
\hline 1993 & Oct-93 & 540 & $\begin{array}{l}\text { Dos programas económicos para 1994: } \\
\text { IIES-UCA y CENITEC }\end{array}$ & $983-1002$ \\
\hline 1994 & Jul-94 & 549 & $\begin{array}{l}\text { Los desacuerdos de la paz: el poder versus } \\
\text { la justicia (Comentario) }\end{array}$ & 691-701 \\
\hline 1995 & Enero-Febrero 1995 & $555-556$ & $\begin{array}{l}\text { ¿Qué modelo económico y qué modelo } \\
\text { de sociedad queremos? }\end{array}$ & $25-50$ \\
\hline 1995 & Enero-Febrero 1995 & $555-556$ & $\begin{array}{l}\text { Releyendo la plataforma económica. } \\
\text { (Comentario) }\end{array}$ & $87-92$ \\
\hline 1995 & Sep-95 & 563 & ¿Recesión económica? & $879-885$ \\
\hline
\end{tabular}




\begin{tabular}{|c|c|c|c|c|}
\hline Año & FECHA & No. & $\begin{array}{c}\text { Nombre del artículo publicado en } \\
\text { revista ECA }\end{array}$ & Págs. \\
\hline 1995 & $\begin{array}{l}\text { Noviembre-Diciembre } \\
1995\end{array}$ & $565-566$ & Los treinta años de la UCA. (Comentario) & $\begin{array}{l}1150- \\
1161\end{array}$ \\
\hline 1996 & Enero-Febrero 1996 & $567-568$ & El año de la modernización:1996 & $59-76$ \\
\hline 1996 & Julio-Agosto 1996 & $573-574$ & ¿Socialismo en hibernación? & $569-597$ \\
\hline 1996 & Oct-96 & 576 & $\begin{array}{l}\text { Propuestas de bienestar ¿con Estado de } \\
\text { bienestar? }\end{array}$ & $865-888$ \\
\hline 1997 & May-97 & 583 & ¿Es ético canonizar la globalización? & $383-402$ \\
\hline 1997 & Sep-97 & 587 & $\begin{array}{l}\text { ¿Es el crecimiento la locomotora de nues- } \\
\text { tra economía? }\end{array}$ & $799-817$ \\
\hline 1998 & Abr-98 & 594 & $\begin{array}{l}\text { Diálogo con las Bases para el plan de } \\
\text { nación. "Las sociedades prósperas son las } \\
\text { que existen en función del ser humano" }\end{array}$ & $319-342$ \\
\hline 1998 & Oct-98 & 600 & Neoliberalismo y globalización & 893-908 \\
\hline 1999 & Mayo-Junio 1999 & $607-608$ & En búsqueda de una tercera vía & $459-474$ \\
\hline 2000 & Enero-Febrero 2000 & $615-616$ & ¿Hacia un pos-neoliberalismo? & $59-77$ \\
\hline 2000 & Enero-Febrero 2000 & $615-616$ & $\begin{array}{l}\text { Davos 2000: la economía es más que } \\
\text { Internet (Comentario) }\end{array}$ & $121-127$ \\
\hline 2000 & Sep-00 & 623 & $\begin{array}{l}\text { La cumbre del milenio: ONU } 2000 \text { (Co- } \\
\text { mentario) }\end{array}$ & $905-910$ \\
\hline 2000 & Oct-00 & 624 & $\begin{array}{l}\text { Praga 2000: ¿un giro copernicano? (Co- } \\
\text { mentario) }\end{array}$ & $\begin{array}{l}1022- \\
1029\end{array}$ \\
\hline 2000 & $\begin{array}{l}\text { Noviembre-Diciembre } \\
2000\end{array}$ & $625-626$ & $\begin{array}{l}\text { Y después vino "la dolarización" (Co- } \\
\text { mentario) }\end{array}$ & $\begin{array}{l}1199- \\
1206\end{array}$ \\
\hline 2001 & Enero-Febrero 2001 & $627-628$ & $\begin{array}{l}\text { Davos y Porto Alegre: debate sobre la } \\
\text { "mundialización" (Comentario) }\end{array}$ & $122-135$ \\
\hline 2001 & Julio-Agosto 2001 & $633-634$ & $\begin{array}{l}\text { El ALCA: acuerdo entre desacuerdos } \\
\text { (Comentario) }\end{array}$ & $699-714$ \\
\hline 2001 & Julio-Agosto 2001 & $633-634$ & $\begin{array}{l}\text { Génova G-7: la globalización impugnada } \\
\text { (Comentario) }\end{array}$ & $715-723$ \\
\hline 2001 & $\begin{array}{l}\text { Noviembre-Diciembre } \\
2001\end{array}$ & $637-638$ & $\begin{array}{l}\text { "Otro mundo es posible". Lección magis- } \\
\text { tral en la investidura como Doctor honoris } \\
\text { causa en economía y ciencias sociales }\end{array}$ & $\begin{array}{l}1043- \\
1051\end{array}$ \\
\hline
\end{tabular}




\begin{tabular}{|c|c|c|c|c|}
\hline Año & FECHA & No. & $\begin{array}{c}\text { Nombre del artículo publicado en } \\
\text { revista ECA }\end{array}$ & Págs. \\
\hline 2002 & Enero-Febrero 2002 & $639-640$ & $\begin{array}{l}\text { Davos, Nueva York y Porto Alegre: ¿pro- } \\
\text { puestas alternativas? }\end{array}$ & $61-77$ \\
\hline 2002 & Sep-02 & 647 & $\begin{array}{l}\text { La cumbre de la tierra en su entorno } \\
\text { mundial }\end{array}$ & $771-784$ \\
\hline 2003 & May-03 & 655 & $\begin{array}{l}\text { Irak y la reconstrucción de Estados } \\
\text { Unidos }\end{array}$ & $385-400$ \\
\hline 2003 & Jun-03 & 656 & $\begin{array}{l}\text { Economía sin plan, sin mercado y sin } \\
\text { autocrítica }\end{array}$ & $541-561$ \\
\hline 2003 & Oct-03 & 660 & $\begin{array}{l}\text { La Organización Mundial del Comercio } \\
\text { de Cancún: un mundo unilateral (Co- } \\
\text { mentario) }\end{array}$ & $\begin{array}{c}1060- \\
1070\end{array}$ \\
\hline 2004 & Enero-Febrero 2004 & $663-664$ & $\begin{array}{l}\text { Un ALCA "a dos velocidades" (Comen- } \\
\text { tario) }\end{array}$ & $145-152$ \\
\hline 2004 & Enero-Febrero 2004 & $663-664$ & $\begin{array}{l}\text { Jornada mundial de la paz "Un compro- } \\
\text { miso siempre actual: educar para la paz". } \\
\text { (Comentario) }\end{array}$ & 153-159 \\
\hline 2004 & Enero-Febrero 2004 & $663-664$ & $\begin{array}{l}\text { La reunión de Monterrey: acuerdo con } \\
\text { desacuerdo (Comentario) }\end{array}$ & $160-163$ \\
\hline 2004 & Julio-Agosto 2004 & $669-670$ & $\begin{array}{l}\text { El acuerdo marco de la OMC, ¿modificar } \\
\text { los tratados de libre comercio? (Comen- } \\
\text { tario) }\end{array}$ & $797-803$ \\
\hline 2004 & Oct-04 & 672 & La "guerra sin fin", un error & $\begin{array}{l}1027- \\
1043\end{array}$ \\
\hline 2004 & $\begin{array}{l}\text { Noviembre-Diciembre } \\
2004\end{array}$ & $673-674$ & $\begin{array}{l}\text { La estrecha ruta hacia la globalización de } \\
\text { la solidaridad }\end{array}$ & $\begin{array}{l}1257- \\
1273\end{array}$ \\
\hline 2005 & Enero-Febrero 2005 & $675-676$ & $\begin{array}{l}\text { Jornada Mundial de la Paz } 2005 \text { (Co- } \\
\text { mentario) }\end{array}$ & $117-124$ \\
\hline 2005 & Mar-05 & 677 & Bush II, Davos y Porto Alegre 2005 & $225-238$ \\
\hline 2005 & Julio-Agosto 2005 & $681-682$ & $\begin{array}{l}\text { El G-8 de Gleneagles: solidaridad versus } \\
\text { terrorismo (Comentario) }\end{array}$ & $707-712$ \\
\hline 2005 & Sep-05 & 683 & $\begin{array}{l}\text { Nueva Orleans: un tercer mundo dentro } \\
\text { del primer mundo (Comentario) }\end{array}$ & $849-853$ \\
\hline 2005 & Sep-05 & 683 & $\begin{array}{l}\text { ¿Por qué decepciona el aniversario } 60 \text { de } \\
\text { Naciones Unidas? (Comentario) }\end{array}$ & $854-865$ \\
\hline 2006 & Ene-06 & 687 & Sin verdad no hay paz ni justicia mundial & $69-86$ \\
\hline 2006 & Ene-06 & 687 & $\begin{array}{l}\text { Crece la conciencia del malestar mundial } \\
\text { en Davos (Comentario) }\end{array}$ & $108-113$ \\
\hline
\end{tabular}




\begin{tabular}{|c|c|c|l|c|}
\hline Año & FECHA & No. & \multicolumn{1}{|c|}{$\begin{array}{c}\text { Nombre del artículo publicado en } \\
\text { revista ECA }\end{array}$} & Págs. \\
\hline 2006 & Febrero-Marzo 2006 & $688-689$ & $\begin{array}{l}\text { El nuevo modelo económico: dos informes } \\
\text { diferentes }\end{array}$ & $317-325$ \\
\hline 2006 & Julio-Agosto 2006 & $693-694$ & $\begin{array}{l}\text { La lucha palestina: silencio y complicidad } \\
\text { internacional (primera parte). (Comen- } \\
\text { tario) }\end{array}$ & $736-751$ \\
\hline 2006 & Septiembre & 695 & $\begin{array}{l}\text { La lucha palestina: silencio y complicidad } \\
\text { internacional (segunda parte). (Comen- } \\
\text { tario) }\end{array}$ & $886-901$ \\
\hline
\end{tabular}

BOLETÍN DE CIENCIAS ECONÓMICAS Y SOCIALES

\begin{tabular}{|c|c|c|c|c|}
\hline Año & Fecha & No. & $\begin{array}{c}\text { Nombre del artículo publicado en } \\
\text { Boletín CCEESS }\end{array}$ & Págs. \\
\hline 1978 & Oct-78 & 5 & Secuestro en la renta nacional & 38 y 44 \\
\hline 1979 & Feb-79 & 9 & $\begin{array}{l}\text { La unión hace la fuerza... La "teoría de la } \\
\text { pendencia" }\end{array}$ & 71 y 74 \\
\hline 1979 & Abr-79 & 11 & $\begin{array}{l}\text { Las "malaventuranzas del empresario": } \\
\text { ¿Incertidumbre o planeación? }\end{array}$ & 85 y 90 \\
\hline 1979 & Sep-79 & 16 & Inflación monetaria y deflación cívica & $\begin{array}{c}125 y \\
130 \\
\end{array}$ \\
\hline 1979 & $\begin{array}{l}\text { Octubre-Noviembre } \\
1979\end{array}$ & 18 & $\begin{array}{l}\text { Nacionalizar: ¿Para qué? Fines y } \\
\text { problemas de la nacionalización }\end{array}$ & 138-139 \\
\hline 1980 & Ene-80 & 20 & $\begin{array}{l}\text { La nacionalización de la banca: ¿Para } \\
\text { qué, y para quiénes? }\end{array}$ & $152-153$ \\
\hline 1980 & Febrero-Marzo 1980 & $21-22$ & $\begin{array}{l}\text { Monseñor Oscar Arnulfo Romero y } \\
\text { Galdámez, "La voz de los sin voz" }\end{array}$ & $159-160$ \\
\hline 1980 & May-80 & 24 & $\begin{array}{l}\text { Josep Broz Tito, inspirador de un nuevo } \\
\text { modelo socialista }\end{array}$ & $\begin{array}{c}178 \text { y } \\
183\end{array}$ \\
\hline 1980 & Junio-Diciembre 1980 & $25-31$ & $\begin{array}{l}\text { 1980: Polonia se declara en huelga, y } \\
\text { Rusia, ¿qué? }\end{array}$ & 191-194 \\
\hline 1980 & Junio-Diciembre 1980 & $25-31$ & $\begin{array}{l}\text { La Facultad de Ciencias Económicas } \\
\text { cumple sus quince años }\end{array}$ & 200 \\
\hline 1981 & Enero-Febrero 1981 & $32-33$ & $\begin{array}{l}\text { El viaje apostólico del papa Juan Pablo } \\
\text { II a Brasil }\end{array}$ & $211-214$ \\
\hline 1981 & Mayo-Junio 1981 & $36-37$ & $\begin{array}{l}\text { La "Vuelta de Francia", 1981: Salen los } \\
\text { centristas y llegan los socialistas }\end{array}$ & $241-242$ \\
\hline 1981 & $\begin{array}{c}\text { Septiembre-Octubre } \\
1981\end{array}$ & $40-41$ & $\begin{array}{l}\text { La teoría de la oferta: ¡Ya se ensayó en los } \\
\text { países pobres! }\end{array}$ & $268-269$ \\
\hline 1982 & Enero-Febrero 1982 & $44-45$ & Polonia: Un punto de reflexión & $295-297$ \\
\hline
\end{tabular}




\begin{tabular}{|c|c|c|c|c|}
\hline Año & Fecha & No. & $\begin{array}{c}\text { Nombre del artículo publicado en } \\
\text { Boletín CCEESS }\end{array}$ & Págs. \\
\hline 1982 & Mayo-Junio 1982 & $48-49$ & 1982: ¿Política versus economía? & $321-322$ \\
\hline 1982 & $\begin{array}{l}\text { Noviembre-Diciembre } \\
1982\end{array}$ & $54-55$ & $\begin{array}{l}\text { A propósito de "La Crisis Económica } \\
\text { Mundial" después de los setenta }\end{array}$ & 396-399 \\
\hline 1983 & Marzo-Abril 1983 & 2 & La economía latinoamericana en 1982 & $107-115$ \\
\hline 1983 & $\begin{array}{c}\text { Noviembre-Diciembre } \\
1983\end{array}$ & 6 & 1983: Evaluación económica & $429-450$ \\
\hline 1985 & Julio-Agosto 1985 & 4 & $\begin{array}{l}\text { La impagable deuda externa } \\
\text { latinoamericana }\end{array}$ & $202-229$ \\
\hline 1986 & Sept-oct 1986. & 5 & $\begin{array}{l}\text { El modelo económico salvadoreño en la } \\
\text { matriz insumo producto: } 1978\end{array}$ & 264-292 \\
\hline
\end{tabular}

REVISTA REALIDAD

\begin{tabular}{|c|c|c|c|c|}
\hline Año & Fecha & No. & $\begin{array}{c}\text { Nombre del artículo publicado en } \\
\text { Revista Realidad }\end{array}$ & Págs. \\
\hline 1988 & Mayo-Junio 1988 & 3 & $\begin{array}{l}\text { "Perestroika": Nuevo modelo para el } \\
\text { mismo sistema y nuevas relaciones entre } \\
\text { distintos sistemas }\end{array}$ & $187-224$ \\
\hline 1990 & Enero-Febrero 1990. & 13 & $\begin{array}{l}\text { ¿Hacia dónde va el Este? y ¿hacia dónde } \\
\text { va el Oeste? }\end{array}$ & $9-43$ \\
\hline 1990 & Mayo-Junio 1990. & 15 & $\begin{array}{l}\text { El programa de Ajuste Estructural: una } \\
\text { herencia difícil }\end{array}$ & $215-239$ \\
\hline 1990 & Julio-Agosto 1990. & 16 & $\begin{array}{l}\text { La ley de privatización bancaria: ¿de la } \\
\text { privatización a la privatización? }\end{array}$ & $333-354$ \\
\hline 1990 & $\begin{array}{l}\text { Noviembre-Diciembre } \\
1990 .\end{array}$ & 18 & $\begin{array}{l}\text { Evolución y evaluación económica de } \\
1990\end{array}$ & $607-639$ \\
\hline 1991 & Enero-Abril 1991. & $19-20$ & El nuevo orden internacional & $11-34$ \\
\hline 1991 & Julio-Agosto 1991. & 22 & $\begin{array}{l}\text { La reconstrucción de postguerra y la } \\
\text { construcción de la paz }\end{array}$ & 439-455 \\
\hline 1991 & $\begin{array}{l}\text { Septiembre-Octubre } \\
1991 .\end{array}$ & 23 & $\begin{array}{l}\text { Del golpe de agosto de } 1991 \text { a los } \\
\text { programas de ajuste estructural en la } \\
\text { URSS }\end{array}$ & $647-696$ \\
\hline 1992 & Mayo-Junio 1992. & 27 & Tecnología para una economía nacional & $329-360$ \\
\hline 1992 & $\begin{array}{c}\text { Septiembre-Octubre } \\
1992 .\end{array}$ & 29 & El neoliberalismo no es un dogma de fe & $485-516$ \\
\hline
\end{tabular}




\begin{tabular}{|c|c|c|c|c|}
\hline Año & Fecha & No. & $\begin{array}{c}\text { Nombre del artículo publicado en } \\
\text { Revista Realidad }\end{array}$ & Págs. \\
\hline 1992 & $\begin{array}{l}\text { Noviembre-Diciembre } \\
1992 .\end{array}$ & 30 & $\begin{array}{l}\text { Entre seguridad y bienestar, entre } \\
\text { consumo e inversión, entre ética y } \\
\text { corrupción: } 1992\end{array}$ & $589-610$ \\
\hline 1993 & Enero-Febrero 1993. & 31 & 1993: El Neosocialismo pide la palabra & $35-67$ \\
\hline 1993 & Marzo-Abril 1993. & 32 & $\begin{array}{l}\text { El plan de reconstrucción nacional son } \\
\text { tres: ¿cuál es el principal? }\end{array}$ & $153-185$ \\
\hline 1993 & Mayo-Junio 1993. & 33 & El reloj de arena marca cuatro años & $331-367$ \\
\hline 1993 & $\begin{array}{c}\text { Septiembre-Octubre } \\
1993 .\end{array}$ & 35 & Piezas para un modelo económico & $495-523$ \\
\hline 1994 & Marzo-Abril 1994. & 38 & El gobierno en los programas de gobierno & $153-181$ \\
\hline 1994 & Mayo-Junio 1994. & 39 & $\begin{array}{l}\text { Aportes económicos de las matrices } \\
\text { 1978-1990 a los programas de desarrollo: } \\
1994-1999\end{array}$ & $303-344$ \\
\hline 1994 & $\begin{array}{l}\text { Noviembre-Diciembre } \\
1994 .\end{array}$ & 42 & $\begin{array}{l}\text { Cumbre mundial sobre el desarrollo } \\
\text { social, 1995: La pobreza el desempleo y } \\
\text { la integración social }\end{array}$ & $841-870$ \\
\hline 1995 & Enero-Febrero 1995 & 43 & $\begin{array}{l}\text { 1994: Sus economías y deseconomías } \\
\text { externas }\end{array}$ & $9-36$ \\
\hline 1997 & Marzo-Abril 1997 & 56 & La modernización del Estado & $103-111$ \\
\hline 1997 & Julio-Agosto 1997 & 58 & La economía imposible & $313-332$ \\
\hline 1998 & Enero-Febrero 1998 & 61 & $\begin{array}{l}\text { Sugerencias al neoliberalismo: haga su } \\
\text { autocrítica }\end{array}$ & $9-32$ \\
\hline 1998 & Mayo-Junio 1998 & 63 & $\begin{array}{l}\text { Lecciones y aplicaciones del Plan de } \\
\text { nación }\end{array}$ & $219-241$ \\
\hline 1999 & Enero-Febrero 1999 & 67 & $\begin{array}{l}\text { Jornada mundial de la paz, 1999. El siglo } \\
\text { XX y los derechos humanos }\end{array}$ & $69-93$ \\
\hline 1999 & Julio-Agosto 1999 & 70 & Estado y plan de nación privado & $397-420$ \\
\hline 1999 & $\begin{array}{c}\text { Septiembre-Octubre } \\
1999\end{array}$ & 71 & $\begin{array}{l}\text { Entre plan y mercado: algo está } \\
\text { cambiando }\end{array}$ & $561-586$ \\
\hline 1999 & $\begin{array}{l}\text { Noviembre-Diciembre } \\
1999\end{array}$ & 72 & $\begin{array}{l}\text { "Nueva Economía-2000": nueva brecha } \\
\text { entre norte-sur }\end{array}$ & $645-672$ \\
\hline 2000 & Mayo-Junio 2000 & 75 & $\begin{array}{l}\text { Teoría general del subempleo, el } \\
\text { desinterés y la moneda }\end{array}$ & $243-276$ \\
\hline
\end{tabular}




\begin{tabular}{|c|c|c|c|c|}
\hline Año & Fecha & No. & $\begin{array}{c}\text { Nombre del artículo publicado en } \\
\text { Revista Realidad }\end{array}$ & Págs. \\
\hline 2000 & $\begin{array}{l}\text { Noviembre-Diciembre } \\
2000\end{array}$ & 78 & $\begin{array}{l}\text { El laberinto económico mundial del } \\
\text { nuevo } 2000\end{array}$ & $635-662$ \\
\hline 2001 & Enero-Febrero 2001 & 79 & La "Turbodolarización" & $9-29$ \\
\hline 2001 & Mayo-Junio 2001 & 81 & $\begin{array}{l}\text { El ALCA: Libre comercio con Plan de } \\
\text { Nación }\end{array}$ & $251-272$ \\
\hline 2001 & Julio-Agosto 2001 & 82 & $\begin{array}{l}\text { Reinventar el Estado y gobernar la } \\
\text { globalización }\end{array}$ & $393-420$ \\
\hline 2001 & $\begin{array}{c}\text { Septiembre-Octubre } \\
2001\end{array}$ & 83 & ENADE 2001: ¿Un compromiso de todos? & $569-591$ \\
\hline 2001 & $\begin{array}{l}\text { Noviembre-Diciembre } \\
2001\end{array}$ & 84 & $\begin{array}{l}\text { Discurso del Padre Francisco Javier Ibisate } \\
\text { S.J. (En agradecimiento por el Doctorado } \\
\text { Honoris Causa otorgado por la UCA) }\end{array}$ & $799-806$ \\
\hline 2002 & Enero-Febrero 2002 & 85 & $\begin{array}{l}11 \text { de septiembre, "Economía del Terror" } \\
\text { y Cumbre de Qatar }\end{array}$ & $7-24$ \\
\hline 2002 & Marzo-Abril 2002 & 86 & $\begin{array}{l}\text { El "Consenso de Monterrey": Financiar el } \\
\text { desarrollo }\end{array}$ & $131-150$ \\
\hline 2002 & Julio-Agosto 2002 & 88 & $\begin{array}{l}\text { La inseguridad: el regulador de la } \\
\text { economía mundial }\end{array}$ & $421-445$ \\
\hline 2002 & Julio-Agosto 2002 & 88 & La globalización anda en pena (editorial) & \\
\hline 2003 & Enero-Febrero 2003 & 91 & Irak en Davos y Porto Alegre 2003 & $11-38$ \\
\hline 2003 & $\begin{array}{l}\text { Noviembre-Diciembre } \\
2003\end{array}$ & 96 & $\begin{array}{l}\text { La } 58^{a} \text { reunión de la ONU: Reforma y } \\
\text { contrarreforma }\end{array}$ & $727-750$ \\
\hline 2004 & Enero-Febrero 2004 & 97 & $\begin{array}{l}\text { La sombra de Bombay se proyecta en } \\
\text { Davos } 2004\end{array}$ & $9-35$ \\
\hline 2004 & Julio-Agosto 2004 & 100 & Editorial: Realidad en su numero cien & \\
\hline 2005 & Enero-Marzo 2005 & 103 & Bush II y la crisis del multilateralismo & $19-50$ \\
\hline 2005 & Abril-junio 2005 & 104 & $\begin{array}{l}\text { Editorial: "Crisis energética": La energía } \\
\text { nuclear, ¿una alternativa complementaria? }\end{array}$ & \\
\hline 2005 & Julio-Septiembre 2005 & 105 & $\begin{array}{l}\text { Hiroshima-Nagasaki, Teherán: la } \\
\text { amenaza nuclear }\end{array}$ & $357-373$ \\
\hline 2005 & Octubre-Diciembre 2005 & 106 & $\begin{array}{l}\text { En Mar de Plata y Hong Kong, "la batalla } \\
\text { económica que se avecina" }\end{array}$ & 599-631 \\
\hline 2006 & Enero-Marzo 2006 & 107 & $\begin{array}{l}\text { Mijail Gorbachov: De la tragedia de } \\
\text { Chernobil a la Carta a la Tierra }\end{array}$ & $11-37$ \\
\hline 2006 & Abril-Junio 2006 & 108 & $\begin{array}{l}\text { ¿Son viables los Objetivos del Milenio en } \\
\text { el entorno mundial del tercer milenio? }\end{array}$ & $221-249$ \\
\hline
\end{tabular}




\begin{tabular}{|c|c|c|l|c|}
\hline Año & Fecha & No. & $\begin{array}{c}\text { Nombre del artículo publicado en } \\
\text { Revista Realidad }\end{array}$ & Págs. \\
\hline 2006 & Julio-Septiembre 2006 & 109 & Los terroristas están ganando la guerra & $347-373$ \\
\hline 2006 & Octubre-Diciembre 2006 & 110 & Salvemos las Naciones Unidas & $501-524$ \\
\hline 2007 & Enero-Marzo 2007 & 111 & $\begin{array}{l}\text { Del libro del Génesis a la Carta de los } \\
\text { Derechos Humanos }\end{array}$ & $15-45$ \\
\hline 2007 & Abril-Junio 2007 & 112 & $\begin{array}{l}\text { Conferencia de Seguridad, Munich 2007: } \\
\text { ¿Cuál es la inseguridad? }\end{array}$ & $185-206$ \\
\hline
\end{tabular}

\section{CARTA A LAS IGLESIAS}

\begin{tabular}{|c|c|c|c|c|}
\hline Año & FECHA & No. & $\begin{array}{c}\text { Nombre del artículo publicado en Carta } \\
\text { a las Iglesias }\end{array}$ & Págs. \\
\hline 1996 & 1-15/enero/1996 & 345 & $\begin{array}{l}\text { La visita de Juan Pablo II a El Salvador } \\
\text { Entrevista con el P. Javier Ibisate S.J., } \\
\text { Rector de la UCA }\end{array}$ & $2-6$ \\
\hline 1996 & 1-15/abril/1996 & 351 & $\begin{array}{l}\text { Entrevista con el P. Francisco Javier } \\
\text { Ibisate, Doctor honoris causa por la } \\
\text { Universidad de Namur, Bélgica }\end{array}$ & $14-16$ \\
\hline 1996 & 16-30/abril/1996 & 352 & $\begin{array}{l}\text { Monseñor Romero: "Con este pueblo no } \\
\text { cuesta ser buen pastor". A propósito del } \\
\text { Buen Pastor y las buenas ovejas }\end{array}$ & $14-15$ \\
\hline 1996 & 16-30/noviembre/1996 & 366 & $\begin{array}{l}\text { Homilía de P. Javier Ibisate, } 15 \text { de } \\
\text { noviembre }\end{array}$ & $15-16$ \\
\hline 1996 & 16-31/diciembre/1996 & 368 & $\begin{array}{l}\text { "Cercano ya el Tercer Milenio" La } \\
\text { esperanza de Juan Pablo II para la } \\
\text { humanidad }\end{array}$ & $12-14$ \\
\hline 1997 & 1-16/marzo/1997 & 373 & $\begin{array}{l}\text { Carta de la UCA al Señor presidente de } \\
\text { México don Ernesto Zedillo (P. Ibisate } \\
\text { era rector) }\end{array}$ & 16 \\
\hline 1997 & 16-30/abril/1997 & 376 & $\begin{array}{l}\text { Entrevista al P. Javier Ibisate, al cesar } \\
\text { como rector de la UCA. }\end{array}$ & $14-15$ \\
\hline 1997 & 16-31/octubre/1997 & 388 & $\begin{array}{l}\text { Homilía del Padre Javier lbisate } 18 \text { de } \\
\text { octubre }\end{array}$ & 11 \\
\hline 1998 & 1-14/febrero/1998 & 395 & $\begin{array}{l}\text { Un nuevo entorno mundial. Comentario } \\
\text { al Mensaje de Paz de Juan Pablo II (I) }\end{array}$ & $11-12$ \\
\hline 1998 & 15-28/febrero/1998 & 396 & $\begin{array}{l}\text { La justicia se fundamenta en el respeto } \\
\text { de los derechos humanos. Comentario al } \\
\text { Mensaje de la Paz de Juan Pablo II (II) }\end{array}$ & $11-12$ \\
\hline 1998 & 1-15/marzo/1998 & 397 & $\begin{array}{l}\text { ¿Globalización en la solidaridad? } \\
\text { Comentario al Mensaje de Paz de Juan } \\
\text { Pablo II (III) }\end{array}$ & $12-13$ \\
\hline 1998 & 16-31/marzo/1998 & 398 & $\begin{array}{l}\text { ¿Globalización en la solidaridad? } \\
\text { Comentario al Mensaje de Paz de Juan } \\
\text { Pablo II (IV) }\end{array}$ & 18-19 \\
\hline
\end{tabular}




\begin{tabular}{|c|c|c|c|c|}
\hline Año & FECHA & No. & $\begin{array}{c}\text { Nombre del artículo publicado en Carta } \\
\text { a las Iglesias }\end{array}$ & Págs. \\
\hline 1998 & 1-15/abril/1998 & 399 & $\begin{array}{l}\text { El compartir, camino hacia la paz. } \\
\text { Comentario al Mensaje de Paz de Juan } \\
\text { Pablo II (y V) }\end{array}$ & $12-13$ \\
\hline 1998 & 1-15/mayo/1998 & 401 & $\begin{array}{l}\text { El buen Pastor da su vida. ¿Y qué dan las } \\
\text { ovejas? }\end{array}$ & $9-1$ \\
\hline 1998 & 15-30/septiembre/1998 & 410 & $\begin{array}{l}\text { La crisis económica internacional en El } \\
\text { Salvador (I) Llueve sobre mojado }\end{array}$ & $6-7$ \\
\hline 1998 & 1-15/octubre/1998 & 411 & $\begin{array}{l}\text { La crisis económica internacional en El } \\
\text { Salvador (II) ¿Se fortalece la estabilidad } \\
\text { económica? }\end{array}$ & 10 \\
\hline 1998 & 16-31/octubre/1998 & 412 & $\begin{array}{l}\text { La crisis económica internacional en El } \\
\text { Salvador (III) La crisis mundial sí nos } \\
\text { puede golpear }\end{array}$ & 11 \\
\hline 1999 & 1-15/enero/1999 & 417 & $\begin{array}{l}\text { Mensaje para la paz de Juan Pablo II El } \\
\text { siglo XX y los Derechos Humanos (I) }\end{array}$ & $6-7$ \\
\hline 1999 & 16-31/enero/1999 & 418 & $\begin{array}{l}\text { Mensaje para la paz de Juan Pablo II El } \\
\text { siglo XX y los Derechos Humanos (II) }\end{array}$ & $9-1$ \\
\hline 1999 & 1-15/febrero/1999 & 419 & $\begin{array}{l}\text { El Papa aterriza en las Américas Los } \\
\text { pecados mortales del continente. }\end{array}$ & $6-8$ \\
\hline 2000 & 1-15/enero/2000 & 441 & $\begin{array}{l}\text { Crítica de Juan Pablo II a la economía } \\
\text { neoliberal }\end{array}$ & 12 \\
\hline 2000 & 1-31/diciembre/2000 & $463-464$ & $\begin{array}{l}\text { La cumbre de Praga y los "nuevos } \\
\text { misioneros" }\end{array}$ & $16-17$ \\
\hline 2001 & 1-15/enero/2001 & 465 & La dolarización y sus consecuencias & 6 \\
\hline 2001 & 1-31/julio/2001 & $477-478$ & Los manifestantes son dos & \\
\hline 2001 & 1-16/agosto/2001 & 479 & Génova de triste recuerdo & \\
\hline 2001 & 17-31/agosto/2001 & 480 & $\begin{array}{l}\text { El Area del Libre Comercio de Las } \\
\text { Américas: sueño o pesadilla }\end{array}$ & 14 \\
\hline 2001 & 16-31/octubre/2001 & 484 & Alimentos con olor a pólvora & \\
\hline 2001 & 1-30/noviembre/2001 & 485 & Ver el mundo desde los pobres & \\
\hline 2003 & 1-30/junio/2003 & 518 & $\begin{array}{l}\text { La oración del Salario Mínimo "Danos } \\
\text { hoy el pan nuestro de cada día" }\end{array}$ & 2 \\
\hline 2003 & 1-30/septiembre/2003 & 521 & $\begin{array}{l}\text { La década de África. Una historia en tres } \\
\text { partes }\end{array}$ & \\
\hline 2003 & 1-31/octubre/2003 & 522 & La OMC de Cancún y el "zar" Zoellikc & 19 \\
\hline 2004 & 1-31/enero/2004 & 525 & La captura de Sadam Hussein & $14-16$ \\
\hline 2004 & $1-29 /$ febrero/2004 & 526 & $\begin{array}{l}\text { El foro social mundial (FSM), Bombay, } \\
\text { 16-21 de enero }\end{array}$ & \\
\hline 2004 & 1-31/agosto/2004 & 532 & Mala herencia económica & \\
\hline 2004 & 1-30/septiembre/2004 & 533 & Dos juicios: Irak y Monseñor Romero & \\
\hline 2005 & 1-31/enero/2005 & 537 & $\begin{array}{l}\text { "El problema más grave es la pobreza, no } \\
\text { el terrorismo" }\end{array}$ & $8-9$ \\
\hline
\end{tabular}




\begin{tabular}{|c|c|c|c|c|}
\hline Año & FECHA & No. & $\begin{array}{c}\text { Nombre del artículo publicado en Carta } \\
\text { a las Iglesias }\end{array}$ & Págs. \\
\hline 2005 & 1-28/febrero/2005 & 538 & $\begin{array}{l}\text { Davos } 2005 \text { anuncia: La guerra a la } \\
\text { pobreza extrema. }\end{array}$ & $8-9$ \\
\hline 2005 & 1-31/julio/2005 & 543 & $\begin{array}{l}\text { La cumbre de G-8 reactiva la agenda del } \\
\text { foro económico de Davos } 2005\end{array}$ & $8-9$ \\
\hline 2005 & 1-31/julio/2005 & 543 & $\begin{array}{l}\text { ¿Un compromiso moral sin caer en el } \\
\text { pánico? }\end{array}$ & $10-11$ \\
\hline 2005 & 1-30/septiembre/2005 & 545 & Los 45 cofrades de la Casa Blanca & \\
\hline 2005 & 1-31/octubre/2005 & 546 & $\begin{array}{l}\text { En los } 60 \text { años de Naciones Unidas: ¿un } \\
\text { fracaso de la ONU? }\end{array}$ & $15-17$ \\
\hline 2005 & 1-30/noviembre/2005 & 547 & $\begin{array}{l}\text { La inconclusa cumbre de las Américas en } \\
\text { Mar del Plata. }\end{array}$ & $16-17$ \\
\hline 2005 & 1-31/diciembre/2005 & 548 & $\begin{array}{l}\text { "Por razones éticas no podemos decir la } \\
\text { verdad" Condoleezza Rice en Europa }\end{array}$ & $6-7$ \\
\hline 2006 & $1-28 /$ febrero/2006 & 550 & La CIA y la tortura & $8-9$ \\
\hline 2006 & 1-31/mayo/2006 & 553 & $\begin{array}{l}\text { Gobiernos de Washington y Londres } \\
\text { alimentan la caldera del terrorismo }\end{array}$ & $6-7$ \\
\hline 2006 & 1-30/junio/2006 & 554 & $\begin{array}{l}\text { A los } 17 \text { años de la masacre de } \\
\text { Tianamen: una lacra del partido } \\
\text { comunista chino }\end{array}$ & $12-13$ \\
\hline 2006 & 1-31/julio/2006 & 555 & $\begin{array}{l}\text { Palestina: "el insoportable peso de la } \\
\text { humillación" }\end{array}$ & $14-15$ \\
\hline 2006 & 1-31/agosto/2006 & 556 & $\begin{array}{l}\text { Israel: "El testamento patriótico" de Ariel } \\
\text { Sharon }\end{array}$ & $6-7$ \\
\hline 2006 & 1-31/octubre/2006 & 558 & $\begin{array}{l}\text { Carta de Vandana Shiva a Coca-Cola y } \\
\text { Pepsi-Cola en la India }\end{array}$ & $8-9$ \\
\hline 2006 & 1-30/noviembre/2006 & 559 & Tragedia en cuatro actos. & $16-17$ \\
\hline
\end{tabular}

SEMANARIO ORIENTACIÓN

\begin{tabular}{|c|c|c|l|c|}
\hline Año & FECHA & No. & \multicolumn{1}{|c|}{$\begin{array}{l}\text { Nombre del artículo publicado en } \\
\text { Semanario Orientación }\end{array}$} & Págs. \\
\hline 1997 & $14 / 09 / 1997$ & 4997 & $\begin{array}{l}\text { El problema de los fraudes financieros en } \\
\text { El Salvador }\end{array}$ & 5 \\
\hline 1997 & $21 / 09 / 1997$ & 4998 & $\begin{array}{l}\text { Antecedentes del problema Insepro } \\
\text { Finsepro }\end{array}$ & 5 \\
\hline 1997 & $28 / 09 / 1997$ & 4999 & $\begin{array}{l}\text { Unas reflexiones en torno al salario } \\
\text { mínimo }\end{array}$ & 5 \\
\hline 1997 & $05 / 10 / 1997$ & 5000 & $\begin{array}{l}\text { Reflexiones sobre la privatizacion de } \\
\text { ANTEL }\end{array}$ & 5 \\
\hline 1997 & $12 / 10 / 1997$ & 5001 & La deuda agraria: ¿Nuestra o de ellos? & 5 \\
\hline 1997 & $19 / 10 / 1997$ & 5002 & $\begin{array}{l}\text { Reflexiones éticas sobre nuestro sistema } \\
\text { bancario }\end{array}$ & 5 \\
\hline 1997 & $26 / 10 / 1997$ & 5003 & Un “Domund" para una globalizacion & 5 \\
\hline 1997 & $02 / 11 / 1997$ & 5004 & El debate en torno a la reducción lel IVA & 5 \\
\hline
\end{tabular}




\begin{tabular}{|c|c|c|c|c|}
\hline Año & FECHA & No. & $\begin{array}{c}\text { Nombre del artículo publicado en } \\
\text { Semanario Orientación }\end{array}$ & Págs. \\
\hline 1997 & 09/11/1997 & 5005 & La evangelización del dinero & 5 \\
\hline 1997 & 16/11/1997 & 5006 & Un Plan Nacional de Desarrollo & 5 \\
\hline 1997 & 23/11/1997 & 5007 & $\begin{array}{l}\text { Cumbre Iberoamericana: himnos a la } \\
\text { democracia }\end{array}$ & 5 \\
\hline 1997 & 07/12/1997 & 5009 & $\begin{array}{l}\text { Los principios económicos de una } \\
\text { sociedad democratica: } 1989-1999\end{array}$ & 5 \\
\hline 1997 & 14/12/1997 & 5010 & $\begin{array}{l}\text { Los principios económicos de una } \\
\text { sociedad democratica: 1989-1999 } \\
\text { (tercera parte) }\end{array}$ & 5 \\
\hline 1998 & 11/01/1998 & 5012 & $\begin{array}{l}\text { Los principios económicos de una } \\
\text { sociedad democratica:1998-1999 } \\
\text { (cuarta parte) }\end{array}$ & 5 \\
\hline 1998 & 18/01/1998 & 5013 & La privatización de la propiedad privada & 5 \\
\hline 1998 & 25/01/1998 & 5014 & $\begin{array}{l}\text { El neoliberalismo en América Latina ) } \\
\text { (primera parte) }\end{array}$ & 5 \\
\hline 1998 & 01/02/1998 & 5015 & $\begin{array}{l}\text { El neoliberalismo en América Latina } \\
\text { (segunda parte) }\end{array}$ & 5 \\
\hline 1998 & 08/02/1998 & 5016 & $\begin{array}{l}\text { El neoliberalismo en América Latina } \\
\text { (tercera parte) }\end{array}$ & 5 \\
\hline 1998 & 15/02/1998 & 5017 & $\begin{array}{l}\text { El neoliberalismo en América Latina } \\
\text { (cuarta parte) }\end{array}$ & 5 \\
\hline 1998 & 22/02/1998 & 5018 & $\begin{array}{l}\text { El neoliberalismo en América Latina } \\
\text { (quinta parte) }\end{array}$ & 5 \\
\hline 1998 & 01/03/1998 & 5019 & $\begin{array}{l}\text { De la justicia de cada uno nace la paz } \\
\text { para todos (Comentario al mensaje del } \\
\text { Papa. Primera parte) }\end{array}$ & 5 \\
\hline 1998 & 08/03/1998 & 5020 & $\begin{array}{l}\text { De la justicia de cada uno nace la paz } \\
\text { para todos (Comentario al mensaje del } \\
\text { Papa. Segunda parte) }\end{array}$ & 5 \\
\hline 1998 & 15/03/1998 & 5021 & $\begin{array}{l}\text { De la justicia de cada uno nace la paz } \\
\text { para todos (Comentario al mensaje del } \\
\text { Papa. Tercera parte) }\end{array}$ & 5 \\
\hline 1998 & 22/03/1998 & 5022 & $\begin{array}{l}\text { De la justicia de cada uno nace la paz } \\
\text { para todos (Comentario al mensaje del } \\
\text { Papa. Cuarta parte) }\end{array}$ & 5 \\
\hline 1998 & 29/03/1998 & 5023 & $\begin{array}{l}\text { De la justicia de cada uno nace la paz } \\
\text { para todos (Comentario al mensaje del } \\
\text { Papa. Quinta parte) }\end{array}$ & 5 \\
\hline 1998 & 05/04/1998 & 5024 & $\begin{array}{l}\text { Plan de Nación: El Salvador, } 1998 . \\
\text { (Primera parte. Presentación) }\end{array}$ & 5 \\
\hline 1998 & 19/04/1998 & 5025 & $\begin{array}{l}\text { Plan de Nación: El Salvador, } 1998 . \\
\text { (Segunda parte) }\end{array}$ & 5 \\
\hline 1998 & 26/04/1998 & 5026 & $\begin{array}{l}\text { Plan de Nación: El Salvador, } 1998 . \\
\text { (Tercera parte) }\end{array}$ & 5 \\
\hline 1998 & 03/05/1998 & 5027 & $\begin{array}{l}\text { Plan de Nación: El Salvador, } 1998 . \\
\text { (Cuarta parte) }\end{array}$ & 5 \\
\hline
\end{tabular}




\begin{tabular}{|c|c|c|c|c|}
\hline Año & FECHA & No. & $\begin{array}{c}\text { Nombre del artículo publicado en } \\
\text { Semanario Orientación }\end{array}$ & Págs. \\
\hline 1998 & 10/05/1998 & 5028 & $\begin{array}{l}\text { Plan de Nación: El Salvador, } 1998 . \\
\text { Quinta parte. }\end{array}$ & 5 \\
\hline 1998 & 17/05/1998 & 5029 & $\begin{array}{l}\text { La segunda Cumbre de las Américas. } \\
\text { Primera parte. }\end{array}$ & 5 \\
\hline 1998 & 24/05/1998 & 5030 & $\begin{array}{l}\text { La segunda Cumbre de las Américas. } \\
\text { Segunda parte. }\end{array}$ & 5 \\
\hline 1998 & $31 / 05 / 1998$ & 5031 & $\begin{array}{l}\text { Las verdades en el discurso del } \\
\text { candidato presidencial: ARENA }\end{array}$ & 5 \\
\hline 1998 & 07/06/1998 & 5032 & $\begin{array}{l}\text { El Salvador son dos: reclamos } \\
\text { departamentales }\end{array}$ & 5 \\
\hline 1998 & 14/06/1998 & 5033 & $\begin{array}{l}\text { El cuarto discurso presidencial: } \\
\text { Reflexiones cívicas. Primera parte. }\end{array}$ & 5 \\
\hline 1998 & 21/06/1998 & 5034 & $\begin{array}{l}\text { El cuarto discurso presidencial: } \\
\text { Reflexiones cívicas. Segunda parte. }\end{array}$ & 5 \\
\hline 1998 & 28/06/1998 & 5035 & La violencia y el desarrollo & 5 \\
\hline 1998 & 19/07/1998 & 5038 & $\begin{array}{l}\text { ¿Es el crecimiento la locomotora de } \\
\text { nuestra economía? }\end{array}$ & 5 \\
\hline 1998 & 26/07/1998 & 5039 & $\begin{array}{l}\text { ¿Es el crecimiento la locomotora de } \\
\text { nuestra economía? -y II- }\end{array}$ & 5 \\
\hline 1998 & 02/08/1998 & 5040 & $\begin{array}{l}\text { La inversión especulativa en el mercado } \\
\text { financiero }\end{array}$ & 5 \\
\hline 1998 & 16/08/1998 & 5041 & $\begin{array}{l}\text { Reflexiones sobre nuestras coyunturas } \\
\text { económicas }\end{array}$ & 5 \\
\hline 1998 & 23/08/1998 & 5042 & El crecimiento con desempleo (I) & 5 \\
\hline 1998 & 30/08/1998 & 5043 & El crecimiento con desempleo (II) & 5 \\
\hline 1998 & 06/09/1998 & 5044 & $\begin{array}{l}\text { Terciarización económica y deterioro } \\
\text { ecológico }\end{array}$ & 5 \\
\hline 1998 & 13/09/1998 & 5045 & $\begin{array}{l}\text { El crédito bancario: otro límite al } \\
\text { crecimiento (I) }\end{array}$ & 5 \\
\hline 1998 & 20/09/1998 & 5046 & $\begin{array}{l}\text { El crédito bancario: otro límite al } \\
\text { crecimiento (y III) }\end{array}$ & 5 \\
\hline 1998 & 27/09/1998 & 5047 & $\begin{array}{l}\text { Crisis internacional golpearía a } \\
\text { El Salvador. Primera parte. }\end{array}$ & 5 \\
\hline 1998 & 04/10/1998 & 5048 & $\begin{array}{l}\text { Crisis internacional golpearía a } \\
\text { El Salvador. Segunda parte (I) }\end{array}$ & 5 \\
\hline 1998 & 11/10/1998 & 5049 & $\begin{array}{l}\text { Crisis internacional golpearía a } \\
\text { El Salvador. Segunda parte (II) }\end{array}$ & 5 \\
\hline 1998 & 18/10/1998 & 5050 & $\begin{array}{l}\text { Crisis internacional golpearía a } \\
\text { El Salvador. La crisis mundial sí nos } \\
\text { puede golpear (I). Tercera parte. }\end{array}$ & 5 \\
\hline 1998 & 01/11/1998 & 5051 & $\begin{array}{l}\text { Sugerencias para el próximo gobierno: } \\
1999 \ldots \text { Primera parte. }\end{array}$ & 6 \\
\hline 1998 & 08/11/1998 & 5052 & $\begin{array}{l}\text { Sugerencias al nuevo gobierno: } 1999 . \\
\text { Segunda parte. }\end{array}$ & 7 \\
\hline
\end{tabular}




\begin{tabular}{|c|c|c|c|c|}
\hline Año & FECHA & No. & $\begin{array}{c}\text { Nombre del artículo publicado en } \\
\text { Semanario Orientación }\end{array}$ & Págs. \\
\hline 1998 & 15/11/1998 & 5053 & La otra crisis. Primera parte. & 7 \\
\hline 1998 & 29/11/1998 & 5054 & La otra crisis. Segunda parte. & 7 \\
\hline 1998 & 06/12/1998 & 5055 & $\begin{array}{l}\text { Informe sobre desarrollo humano-1998. } \\
\text { El consumo desigual (Naciones Unidas) }\end{array}$ & 7 \\
\hline 1998 & 13/12/1998 & 5056 & $\begin{array}{l}\text { El consumo desigual (PNUD). Primera } \\
\text { parte. }\end{array}$ & 7 \\
\hline 1998 & 20/12/1998 & 5057 & $\begin{array}{l}\text { El consumo desigual (PNUD). Segunda } \\
\text { parte }\end{array}$ & 7 \\
\hline 1999 & 10/01/1999 & 5059 & $\begin{array}{l}\text { El consumo desigual (PNUD). Tercera } \\
\text { parte. }\end{array}$ & 7 \\
\hline 1999 & 17/01/1999 & 5060 & $\begin{array}{l}\text { El siglo XX y los derechos humanos. } \\
\text { Primera parte. }\end{array}$ & 7 \\
\hline 1999 & 24/01/1999 & 5061 & $\begin{array}{l}\text { El siglo XX y los derechos humanos. } \\
\text { Segunda parte. }\end{array}$ & 7 \\
\hline 1999 & $31 / 01 / 1999$ & 5062 & $\begin{array}{l}\text { El siglo XX y los derechos humanos. } \\
\text { El derecho a la paz. Tercera parte }\end{array}$ & 7 \\
\hline 1999 & 07/02/1999 & 5063 & $\begin{array}{l}\text { El siglo XX y los derechos humanos. } \\
\text { Progreso global en solidaridad. Cuarta } \\
\text { parte. }\end{array}$ & 7 \\
\hline 1999 & 14/02/1999 & 5064 & $\begin{array}{l}\text { Foro de Davos analizará globalización. } \\
\text { Primera parte. }\end{array}$ & 7 \\
\hline 1999 & $21 / 02 / 1999$ & 5065 & $\begin{array}{l}\text { Foro de Davos analizará globalización. } \\
\text { Segunda parte. }\end{array}$ & 7 \\
\hline 1999 & 07/03/1999 & 5067 & $\begin{array}{l}\text { Amanece la participación ciudadana. } \\
\text { Primera parte. }\end{array}$ & 7 \\
\hline 1999 & 14/03/1999 & 5068 & $\begin{array}{l}\text { Amanece la participación ciudadana. } \\
\text { Segunda parte. }\end{array}$ & 7 \\
\hline 1999 & 21/03/1999 & 5068 & $\begin{array}{l}\text { Amanece la participación ciudadana. } \\
\text { Tercera parte. }\end{array}$ & 14 \\
\hline 1999 & 28/03/1999 & 5070 & $\begin{array}{l}\text { Amanece la participación ciudadana. } \\
\text { Cuarta parte. }\end{array}$ & 7 \\
\hline 1999 & $11 / 04 / 1999$ & 5071 & $\begin{array}{l}\text { Amanece la participación ciudadana. } \\
\text { La crisis del medio ambiente. } \\
\text { Quinta parte. }\end{array}$ & 7 \\
\hline 1999 & 25/04/1999 & 5072 & Sí a la vida, no a la deuda. Primera parte. & 7 \\
\hline 1999 & 02/05/1999 & 5074 & $\begin{array}{l}\text { Sí a la vida, no a la deuda. Segunda } \\
\text { parte. }\end{array}$ & 7 \\
\hline 1999 & 09/05/1999 & 5075 & Sí a la vida, no a la deuda. Tercera parte. & 7 \\
\hline 1999 & 16/05/1999 & 5076 & $\begin{array}{l}\text { Crecimiento con participación. Una } \\
\text { estrategia de desarrollo. Primera parte. }\end{array}$ & 7 \\
\hline 1999 & 23/05/1999 & 5077 & $\begin{array}{l}\text { Crecimiento con participación. Una } \\
\text { estrategia de desarrollo. Segunda parte. }\end{array}$ & 7 \\
\hline 1999 & 06/06/1999 & 5079 & $\begin{array}{l}\text { Estado de la nación en desarrollo } \\
\text { humano. Primera parte. }\end{array}$ & 7 \\
\hline 1999 & 13/06/1999 & 5080 & $\begin{array}{l}\text { estado de la nación en desarrollo } \\
\text { humano (segunda parte) participación } \\
\text { de la gente. unas pinceladas sueltas... }\end{array}$ & 7 \\
\hline
\end{tabular}




\begin{tabular}{|c|c|c|c|c|}
\hline Año & FECHA & No. & $\begin{array}{c}\text { Nombre del artículo publicado en } \\
\text { Semanario Orientación }\end{array}$ & Págs. \\
\hline 1999 & 20/06/1999 & 5081 & $\begin{array}{l}\text { Estado de la nación en desarrollo } \\
\text { humano. Seguridad humana: otras } \\
\text { pinceladas. Tercera parte. }\end{array}$ & 7 \\
\hline 1999 & 27/06/1999 & 5082 & $\begin{array}{l}\text { Estado de la nación en desarrollo } \\
\text { humano. Cuarta parte. }\end{array}$ & 7 \\
\hline 1999 & 04/07/1999 & 5083 & La seguridad humana: algunas amenazas & 7 \\
\hline 1999 & 11/07/1999 & 5084 & Crímenes de guerra. Primera parte & 7 \\
\hline 1999 & 18/07/1999 & 5085 & $\begin{array}{l}\text { "Ninguna guerra es humana". Segunda } \\
\text { parte. }\end{array}$ & 7 \\
\hline 1999 & 25/07/1999 & 5086 & "Guerra e hipocresía". Tercera parte. & 7 \\
\hline 1999 & 01/08/1999 & 5087 & $\begin{array}{l}\text { "Del humanitarismo al superpoder } \\
\text { mundial". Cuarta parte. }\end{array}$ & 7 \\
\hline 1999 & 15/08/1999 & 5088 & (Primera parte) Presentación & 7 \\
\hline 1999 & 22/08/1999 & 5089 & $\begin{array}{l}\text { Una economía "dolarizada". Segunda } \\
\text { parte. }\end{array}$ & 7 \\
\hline 1999 & 05/09/1999 & 5091 & (Cuarta parte) ¿Y la crisis financiera? & 7 \\
\hline 1999 & 19/09/1999 & 5093 & Estamos en crisis... Primera parte. & 7 \\
\hline 1999 & 26/09/1999 & 5094 & $\begin{array}{l}\text { Estamos en crisis interna... Segunda } \\
\text { parte. }\end{array}$ & 7 \\
\hline 1999 & 03/10/1999 & 5095 & Las encuestas. Tercera parte. & 7 \\
\hline 1999 & 10/10/1999 & 5096 & $\begin{array}{l}\text { ¿Qué dicen encuestas y entrevistas? } \\
\text { Cuarta parte. }\end{array}$ & 7 \\
\hline 1999 & 17/10/1999 & 5097 & $\begin{array}{l}\text { ¿Vamos a mejor o vamos a Dios sabe a } \\
\text { dónde? Primera parte. }\end{array}$ & 7 \\
\hline 1999 & 24/10/1999 & 5098 & $\begin{array}{l}\text { Subempleo, salarios reales, } \\
\text { estancamiento de los precios. Segunda } \\
\text { parte. }\end{array}$ & 7 \\
\hline 1999 & 31/10/1999 & 5099 & La morosidad bancaria. Tercera parte. & 7 \\
\hline 1999 & 07/11/1999 & 5100 & $\begin{array}{l}\text { El déficit fiscal y la danza de los } \\
\text { millones. Cuarta parte. }\end{array}$ & 7 \\
\hline 1999 & 14/11/1999 & 5101 & $\begin{array}{l}\text { El déficit comercial y el salvataje de "los } \\
\text { pobre-dólares". Quinta parte. }\end{array}$ & 7 \\
\hline 1999 & 21/11/1999 & 5102 & $\begin{array}{l}\text { El fondo monetario internacional y el } \\
\text { "clamor de los pobres". Primera parte. }\end{array}$ & 7 \\
\hline 1999 & 05/12/1999 & 5104 & $\begin{array}{l}\text { "Se predica la buena nueva a los } \\
\text { pobres". Primera parte. }\end{array}$ & 7 \\
\hline 1999 & 12/12/1999 & 5105 & $\begin{array}{l}\text { "Se predica la buena nueva a los } \\
\text { pobres". Segunda parte. }\end{array}$ & 7 \\
\hline 1999 & 19/12/1999 & 5106 & $\begin{array}{l}\text { ¿Se predicará la buena nueva a los } \\
\text { pobres?". Tercera parte. }\end{array}$ & 10 \\
\hline 2000 & 09/01/2000 & 5108 & El clamor de los pobres en cifras & 7 \\
\hline 2000 & 16/01/2000 & 5109 & Una paz sin exclusión (I) & 7 \\
\hline
\end{tabular}




\begin{tabular}{|c|c|c|c|c|}
\hline Año & FECHA & No. & $\begin{array}{c}\text { Nombre del artículo publicado en } \\
\text { Semanario Orientación }\end{array}$ & Págs. \\
\hline 2000 & 23/01/2000 & 5110 & Una economía sin exclusión (II) & 7,15 \\
\hline 2000 & $04 / 02 / 2000$ & 5111 & $\begin{array}{l}\text { Una economía sin exclusión (III) } \\
\text { ¿Es posible una economía sin exclusión } \\
\text { en El Salvador? }\end{array}$ & 7,15 \\
\hline 2000 & 06/02/2000 & 5112 & $\begin{array}{l}\text { Cuadratura del círculo y soluciones para } \\
\text { el Sur (III) }\end{array}$ & 7 \\
\hline 2000 & $13 / 02 / 2000$ & 5113 & $\begin{array}{l}\text { Deuda externa: algunas preguntas claves } \\
\text { (IV) }\end{array}$ & 7 \\
\hline 2000 & $20 / 02 / 2000$ & 5114 & $\begin{array}{l}\text { Deuda externa: algunas preguntas claves } \\
\text { (V) }\end{array}$ & 7 \\
\hline 2000 & $27 / 02 / 2000$ & 5115 & $\begin{array}{l}\text { Última pregunta: ¿por qué no quieren } \\
\text { perdonar }(\mathrm{VI})\end{array}$ & 7 \\
\hline 2000 & 05/03/2000 & 5116 & ¿De igual a peor? & 7 \\
\hline 2000 & $12 / 03 / 2000$ & 5117 & ¿Cómo terminó la economía de $1999 ?$ & 7 \\
\hline 2000 & 19/03/2000 & 5118 & Digámos y hagámos la verdad & 7 \\
\hline 2000 & 09/04/2000 & 5121 & "La pobreza en el mundo". Primera parte & 7 \\
\hline 2000 & 16/04/2000 & 5122 & $\begin{array}{l}\text { La cumbre del Desarrollo y del } \\
\text { Comercio. Bangkok. Los duros de } \\
\text { corazón. Segunda parte. }\end{array}$ & 6 \\
\hline 2000 & 07/05/2000 & 5124 & $\begin{array}{l}\text { "El hombre de Davos" y "el hombre de } \\
\text { Seattle". Los duros de corazón. Tercera } \\
\text { parte. }\end{array}$ & 7 \\
\hline 2000 & $21 / 05 / 2000$ & 5126 & En búsqueda de la Utopía & 7 \\
\hline 2000 & 28/05/2000 & 5127 & $\begin{array}{l}\text { La Utopía en la reunión de Washington: } \\
\text { FMI y Banco Mundial. La reunión de } \\
\text { "primavera". Segunda parte }\end{array}$ & 7 \\
\hline 2000 & $04 / 06 / 2000$ & 5128 & $\begin{array}{l}\text { En búsqueda de la "utopía". El FMI y } \\
\text { el Banco Mundial entre la espada y la } \\
\text { pared. Tercera parte. }\end{array}$ & 7 \\
\hline 2000 & $25 / 06 / 2000$ & 5131 & $\begin{array}{l}\text { El "Pentecostés" de la economía. Primera } \\
\text { parte. }\end{array}$ & 7 \\
\hline 2000 & 02/07/2000 & 5132 & $\begin{array}{l}\text { Antes del primer año de gobierno. } \\
\text { Segunda parte. }\end{array}$ & 7 \\
\hline 2000 & 09/07/2000 & 5133 & $\begin{array}{l}\text { Antes del primer año de gobierno. } \\
\text { Tercera parte. }\end{array}$ & 7 \\
\hline 2000 & 16/07/2000 & 5134 & $\begin{array}{l}\text { Los programas externos de reforma } \\
\text { económica. Cuarta parte. }\end{array}$ & 7 \\
\hline 2000 & $23 / 07 / 2000$ & 5135 & Las políticas sectoriales. Quinta parte. & 7 \\
\hline 2000 & 20/08/2000 & 5138 & $\begin{array}{l}\text { Desarrollo más allá de la economía. } \\
\text { Primera parte. }\end{array}$ & 7 \\
\hline 2000 & $27 / 08 / 2000$ & 5139 & $\begin{array}{l}\text { El derecho a tener derechos. Segunda } \\
\text { parte. }\end{array}$ & 10 \\
\hline 2000 & 03/09/2000 & 5140 & $\begin{array}{l}\text { Organismos contra la pobreza. Tercera } \\
\text { parte. }\end{array}$ & 7 \\
\hline
\end{tabular}




\begin{tabular}{|c|c|c|c|c|}
\hline Año & FECHA & No. & $\begin{array}{c}\text { Nombre del artículo publicado en } \\
\text { Semanario Orientación }\end{array}$ & Págs. \\
\hline 2000 & $10 / 09 / 2000$ & 5141 & $\begin{array}{l}\text { Capitalismo frente a democracia. } \\
\text { Cuarta parte. }\end{array}$ & 7 \\
\hline 2000 & $17 / 09 / 2000$ & 5142 & $\begin{array}{l}\text { Desarrollo más allá de economía. } \\
\text { Quinta parte. }\end{array}$ & 7 \\
\hline 2000 & $24 / 09 / 2000$ & 5143 & Segundo trimestre peor. Sexta parte. & 7 \\
\hline 2000 & $01 / 10 / 2000$ & 5144 & $\begin{array}{l}\text { ¿La cumbre de la esperanza? } \\
\text { Primera parte. }\end{array}$ & 7 \\
\hline 2000 & $08 / 10 / 2000$ & 5145 & $\begin{array}{l}\text { Kofi Annan: Una reunión de trabajo. } \\
\text { Segunda parte. }\end{array}$ & 7 \\
\hline 2000 & $15 / 10 / 2000$ & 5146 & $\begin{array}{l}\text { Bill Clinton: Lo escrito escrito está. } \\
\text { Tercera parte. }\end{array}$ & 7 \\
\hline 2000 & $22 / 10 / 2000$ & 5147 & $\begin{array}{l}\text { El Consejo de Seguridad de las Naciones } \\
\text { Unidas. Cuarta parte. }\end{array}$ & 7 \\
\hline 2000 & $29 / 10 / 2000$ & 5148 & $\begin{array}{l}\text { Manifestantes y algunas conclusiones. } \\
\text { Quinta parte. }\end{array}$ & 7 \\
\hline 2000 & $05 / 11 / 2000$ & 5149 & $\begin{array}{l}\text { Desarrollo más allá de la economía. } \\
\text { Sexta parte. }\end{array}$ & 7 \\
\hline 2000 & $12 / 11 / 2000$ & 5150 & $\begin{array}{l}\text { Reducir la pobreza a la mitad para el año } \\
\text { 2015. Última parte. }\end{array}$ & 7 \\
\hline 2000 & $03 / 12 / 2000$ & 5153 & $\begin{array}{l}\text { Presentando a los misioneros. Primera } \\
\text { parte. }\end{array}$ & 11 \\
\hline 2000 & $10 / 12 / 2000$ & 5154 & $\begin{array}{l}\text { La predicación de los manifestantes. } \\
\text { Segunda parte. }\end{array}$ & 7 \\
\hline 2000 & $17 / 12 / 2000$ & 5155 & Dudas y expectativas. Presentación. & 7 \\
\hline 2000 & $24 / 12 / 2000$ & 5156 & La integración monetaria. Segunda parte. & 7 \\
\hline 2001 & 07/01/2001 & 5157 & La integración monetaria. Tercera parte. & 5 \\
\hline 2001 & 14/01/2001 & 5158 & $\begin{array}{l}\text { La dolarización monetaria, por sí sola, no } \\
\text { es la solución. Cuarta parte. }\end{array}$ & 16 \\
\hline 2001 & $21 / 01 / 2001$ & 5159 & La predicación de los manifestantes & 9 \\
\hline 2001 & 28/01/2001 & 5160 & Praga ¿un "giro copérnico"? & 7 \\
\hline 2001 & $04 / 02 / 2001$ & 5161 & La voz de la naturaleza & 7 \\
\hline 2001 & $18 / 02 / 2001$ & 5163 & ¿Politización del dolor? & 16 \\
\hline 2001 & $25 / 02 / 2001$ & 5164 & $\begin{array}{l}\text { Una economía "desde los pobres". } \\
\text { Tercera parte. }\end{array}$ & 16 \\
\hline 2001 & 04/03/2001 & 5165 & $\begin{array}{l}\text { Unidos para construir un nuevo } \\
\text { El Salvador. Primera parte. }\end{array}$ & 16 \\
\hline 2001 & $11 / 03 / 2001$ & 5166 & $\begin{array}{l}\text { Unidos para construir un nuevo } \\
\text { El Salvador. "La concertación en ruinas" } \\
\text { Segunda parte. }\end{array}$ & 7 \\
\hline 2001 & 18/03/2001 & 5167 & $\begin{array}{l}\text { Unidos para construir un nuevo } \\
\text { El Salvador. Declaración ciudadana. } \\
\text { Tercera parte. }\end{array}$ & 7 \\
\hline
\end{tabular}




\begin{tabular}{|c|c|c|c|c|}
\hline Año & FECHA & No. & $\begin{array}{c}\text { Nombre del artículo publicado en } \\
\text { Semanario Orientación }\end{array}$ & Págs. \\
\hline 2001 & 08/04/2001 & 5170 & Dos documentos oficiales. Primera parte. & 7 \\
\hline 2001 & $22 / 04 / 2001$ & 5171 & $\begin{array}{l}\text { ¿Pobres elegantes o pobres de verdad? } \\
\text { Segunda parte. }\end{array}$ & 7 \\
\hline 2001 & 29/04/2001 & 5172 & $\begin{array}{l}\text { ¿Unidos para El Salvador? } \\
\text { Reconstrucción con desarrollo. Tercera } \\
\text { parte. }\end{array}$ & 13 \\
\hline 2001 & 06/05/2001 & 5173 & $\begin{array}{l}\text { ¿Unidos para El Salvador? ¿Unidos para } \\
\text { el financiamiento?. Cuarta parte. }\end{array}$ & 16 \\
\hline 2001 & 20/05/2001 & 5175 & $\begin{array}{l}\text { Primer reto: Disminuir la pobreza. Banco } \\
\text { mundial. Primera parte. }\end{array}$ & 7 \\
\hline 2001 & $27 / 05 / 2001$ & 5176 & $\begin{array}{l}\text { Precondiciones para el alivio de la } \\
\text { pobreza. Segunda parte. }\end{array}$ & 7 \\
\hline 2001 & 03/06/2001 & 5177 & $\begin{array}{l}\text { Otras precondiciones para el alivio de la } \\
\text { pobreza. Tercera parte. }\end{array}$ & 7 \\
\hline 2001 & 10/06/2001 & 5178 & $\begin{array}{l}\text { Las precondiciones públicas y sociales. } \\
\text { Cuarta parte. }\end{array}$ & 7 \\
\hline 2001 & 01/07/2001 & 5181 & $\begin{array}{l}\text { Hemos firmado varios tratados } \\
\text { comerciales. Primera parte. }\end{array}$ & 7 \\
\hline 2001 & 08/07/2001 & 5182 & $\begin{array}{l}\text { Libre comercio, pobreza y democracia. } \\
\text { Segunda parte. }\end{array}$ & 7 \\
\hline 2001 & 15/07/2001 & 5183 & $\begin{array}{l}\text { Los anexos del ALCA: Un Plan de } \\
\text { Nación. Tercera parte. }\end{array}$ & 7 \\
\hline 2001 & $22 / 07 / 2001$ & 5184 & $\begin{array}{l}\text { Más anexos para un Plan de Nación. } \\
\text { Cuarta parte. }\end{array}$ & 7 \\
\hline 2001 & 29/07/2001 & 5185 & $\begin{array}{l}\text { Los requisitos no comerciales del } \\
\text { comercio mundial. Última parte. }\end{array}$ & 7 \\
\hline 2001 & 12/08/2001 & 5186 & Desarrollo y capital social. Primera parte. & 7 \\
\hline 2001 & 19/08/2001 & 5187 & $\begin{array}{l}\text { Nuestro desarrollo desde "El capital } \\
\text { social". Segunda parte. }\end{array}$ & 7 \\
\hline 2001 & 26/08/2001 & 5188 & $\begin{array}{l}\text { Se diluyen las expectativas de los } \\
\text { Acuerdos de Paz. Tercera parte. }\end{array}$ & 7 \\
\hline 2001 & 02/09/2001 & 5189 & $\begin{array}{l}\text { Déficit de confianza y de credibilidad. } \\
\text { Cuarta parte. }\end{array}$ & 7 \\
\hline 2001 & 09/09/2001 & 5190 & Presentación de la agenda. Primera parte. & 7 \\
\hline 2001 & 16/09/2001 & 5191 & Las tres injusticias. Segunda parte. & 7 \\
\hline 2001 & 23/09/2001 & 5192 & $\begin{array}{l}\text { Un orden del día para el grupo G-7. } \\
\text { Tercera parte. }\end{array}$ & 7 \\
\hline 2001 & 30/09/2001 & 5193 & $\begin{array}{l}\text { Un orden del día para el grupo G-7 (b). } \\
\text { Cuarta parte. }\end{array}$ & 7 \\
\hline 2001 & 07/10/2001 & 5194 & $\begin{array}{l}\text { La economía mundial anda mal. } \\
\text { Quinta parte. }\end{array}$ & 7 \\
\hline 2001 & 14/10/2001 & 5195 & $\begin{array}{l}\text { El papel de la conciencia ciudadana. } \\
\text { Sexta parte. }\end{array}$ & 7 \\
\hline
\end{tabular}




\begin{tabular}{|c|c|c|c|c|}
\hline Año & FECHA & No. & $\begin{array}{c}\text { Nombre del artículo publicado en } \\
\text { Semanario Orientación }\end{array}$ & Págs. \\
\hline 2001 & $21 / 10 / 2001$ & 5196 & $\begin{array}{l}\text { Del terrorismo, líbranos, Señor. Primera } \\
\text { parte. }\end{array}$ & 7 \\
\hline 2001 & 28/10/2001 & 5197 & $\begin{array}{l}\text { Terrorismo antes del } 11 \text { de septiembre. } \\
\text { Segunda parte. }\end{array}$ & 7 \\
\hline 2001 & $04 / 11 / 2001$ & 5198 & $\begin{array}{l}\text { No definen qué es terrorismo. } \\
\text { Tercera parte. }\end{array}$ & 7 \\
\hline 2001 & $11 / 11 / 2001$ & 5199 & $\begin{array}{l}\text { ¿Cómo nos afectará el } 11 \text { de septiembre? } \\
\text { Cuarta parte. }\end{array}$ & 7 \\
\hline 2001 & 18/11/2001 & 5200 & $\begin{array}{l}\text { Dos economías en recesión. } \\
\text { Primera parte. }\end{array}$ & 7 \\
\hline 2001 & $25 / 11 / 2001$ & 5201 & $\begin{array}{l}\text { Impacto a nivel nacional y continental. } \\
\text { Segunda parte. }\end{array}$ & 7 \\
\hline 2001 & $02 / 12 / 2001$ & 5202 & $\begin{array}{l}\text { Impacto a nivel nacional y continental. } \\
\text { Tercera parte. }\end{array}$ & 10 \\
\hline 2001 & $09 / 12 / 2001$ & 5203 & $\begin{array}{l}\text { Documentos y testimonios nacionales. } \\
\text { Cuarta parte. }\end{array}$ & 7 \\
\hline 2001 & 16/12/2001 & 5204 & Reflexiones finales. Quinta parte. & 7 \\
\hline 2001 & 23/12/2001 & 5205 & El rebote del terrorismo. Primera parte. & 7 \\
\hline 2002 & 06/01/2002 & 5206 & Los terrorismos son más. Segunda parte. & 4 \\
\hline 2002 & 13/01/2002 & 5207 & $\begin{array}{l}\text { "Misterium iniquitatis". El misterio del } \\
\text { mal. Primera parte. }\end{array}$ & 7 \\
\hline 2002 & 20/01/2002 & 5208 & $\begin{array}{l}\text { El derecho de defensa contra el } \\
\text { terrorismo. Segunda parte. }\end{array}$ & 7 \\
\hline 2002 & $27 / 01 / 2002$ & 5209 & Mirarse en el espejo. Tercera parte. & 7 \\
\hline 2002 & 03/02/2002 & 5210 & $\begin{array}{l}\text { La Cumbre Comercial de Qatar. Cuarta } \\
\text { parte. }\end{array}$ & 7 \\
\hline 2002 & $17 / 02 / 2002$ & 5212 & $\begin{array}{l}\text { Los resultados de la cumbre de la OMC } \\
\text { en Qatar }\end{array}$ & 13 \\
\hline 2002 & 03/03/2002 & 5214 & Davos en Nueva York. Primera parte. & 7 \\
\hline 2002 & 17/03/2002 & 5216 & $\begin{array}{l}\text { "Bush relanza la guerra contra el } \\
\text { terrorismo". Segunda parte. }\end{array}$ & 7 \\
\hline 2002 & 07/04/2002 & 5218 & $\begin{array}{l}\text { Más reacciones al discurso de Bush ante } \\
\text { el congreso. Tercera parte. }\end{array}$ & 7 \\
\hline 2002 & $14 / 04 / 2002$ & 5219 & $\begin{array}{l}\text { "Desacuerdos en el Foro Económico } \\
\text { Mundial". Cuarta parte. }\end{array}$ & 7 \\
\hline 2002 & $21 / 04 / 2002$ & 5220 & $\begin{array}{l}\text { El Foro Social Mundial de Porto Alegre. } \\
\text { Quinta parte. }\end{array}$ & 7 \\
\hline 2002 & 28/04/2002 & 5221 & $\begin{array}{l}\text { Un programa que es una propuesta. } \\
\text { Última parte. }\end{array}$ & 7 \\
\hline 2002 & 05/05/2002 & 5222 & $\begin{array}{l}\text { "Globalizar la solidaridad". } \\
\text { Primera parte. }\end{array}$ & 7 \\
\hline 2002 & $12 / 05 / 2002$ & 5223 & Financiar el desarrollo. Segunda parte. & 7 \\
\hline 2002 & 19/05/2002 & 5224 & $\begin{array}{l}\text { La defensa de la solidaridad. } \\
\text { Tercera parte. }\end{array}$ & 7 \\
\hline 2002 & 26/05/2002 & 5225 & Divergencias en Monterrey. Cuarta parte. & 7 \\
\hline
\end{tabular}




\begin{tabular}{|c|c|c|c|c|}
\hline Año & FECHA & No. & $\begin{array}{l}\text { Nombre del artículo publicado en } \\
\text { Semanario Orientación }\end{array}$ & Págs. \\
\hline 2002 & 02/06/2002 & 5226 & $\begin{array}{l}\text { "El evangelio del comercio exterior". } \\
\text { Quinta parte. }\end{array}$ & 7 \\
\hline 2002 & 09/06/2002 & 5227 & $\begin{array}{l}\text { La corrupción, un obstáculo para salir de } \\
\text { la pobreza. Sexta parte. }\end{array}$ & 7 \\
\hline 2002 & 16/06/2002 & 5228 & $\begin{array}{l}\text { Sin respuestas de Monterrey. Séptima y } \\
\text { última parte. }\end{array}$ & 7 \\
\hline 2002 & 23/06/2002 & 5229 & Las nuevas amenazas. Primera parte. & 7 \\
\hline 2002 & $30 / 06 / 2002$ & 5230 & El nacional integrismo. Segunda parte. & 7 \\
\hline 2002 & 07/07/2002 & 5231 & $\begin{array}{l}\text { La inseguridad: el regulador de la } \\
\text { economía mundial. Tercera parte. }\end{array}$ & 7 \\
\hline 2002 & $14 / 07 / 2002$ & 5232 & "El consejo Rusia-OTAN". Cuarta parte. & 7 \\
\hline 2002 & $21 / 07 / 2002$ & 5233 & $\begin{array}{l}\text { La post-data de los olvidados. La cumbre } \\
\text { de Madrid. Última parte. }\end{array}$ & 7 \\
\hline 2002 & 08/09/2002 & 5239 & Jeremías 2002. Primera parte. & 7 \\
\hline 2002 & 15/09/2002 & 5240 & ¿Tambores de guerra? Segunda parte. & 7 \\
\hline 2002 & 22/09/2002 & 5241 & Nuevas controversias. Tercera parte. & 7 \\
\hline 2002 & 06/10/2002 & 5243 & No somos extraterrestres. Primera parte. & 7 \\
\hline 2002 & 13/10/2002 & 5244 & $\begin{array}{l}\text { La declaración de Johannesburgo. } \\
\text { Segunda parte. }\end{array}$ & 7 \\
\hline 2002 & 20/10/2002 & 5245 & "Salvar el planeta". Tercera parte. & 7 \\
\hline 2002 & $27 / 10 / 2002$ & 5246 & $\begin{array}{l}\text { "Nuestra casa está ardiendo". } \\
\text { Cuarta Parte. }\end{array}$ & 7 \\
\hline 2002 & $03 / 11 / 2002$ & 5247 & "Nos lo agradecerá". Quinta Parte. & 7 \\
\hline 2002 & 10/11/2002 & 5248 & El protocolo de Kyoto. Sexta Parte. & 7 \\
\hline 2002 & $17 / 11 / 2002$ & 5249 & $\begin{array}{l}\text { Después de Quatar sigue Qatar. Séptima } \\
\text { Parte. }\end{array}$ & 7 \\
\hline 2002 & $24 / 11 / 2002$ & 5250 & El terrorismo de cuello blanco & 7 \\
\hline 2002 & 01/12/2002 & 5251 & $\begin{array}{l}\text { A los dos años de la dolarización. } \\
\text { Primera parte. }\end{array}$ & 7 \\
\hline 2002 & 08/12/2002 & 5252 & $\begin{array}{l}\text { ¿Se ha reactivado nuestra economía? } \\
\text { Segunda parte. }\end{array}$ & 7 \\
\hline 2002 & $15 / 12 / 2002$ & 5253 & $\begin{array}{l}\text { Efectos de las bajas tasas de interés. } \\
\text { Tercera parte. }\end{array}$ & 7 \\
\hline 2002 & $22 / 12 / 2002$ & 5254 & $\begin{array}{l}\text { ¿Salvadoreños gozan de bajos intereses? } \\
\text { Cuarta parte. }\end{array}$ & 7 \\
\hline 2003 & 05/01/2003 & 5255 & $\begin{array}{l}\text { "Un modelo que no funciona". } \\
\text { Quinta parte. }\end{array}$ & 5 \\
\hline 2003 & $26 / 01 / 2003$ & 5258 & "Construir la Confianza". Primera parte. & 7 \\
\hline 2003 & $02 / 02 / 2003$ & 5259 & "Construir la Confianza". Segunda parte. & 7 \\
\hline 2003 & 09/02/2003 & 5260 & $\begin{array}{l}\mathrm{Ni} \text { competencia, ni honestidad. } \\
\text { Tercera parte. }\end{array}$ & 7 \\
\hline 2003 & 16/02/2003 & 5261 & $\begin{array}{l}\text { La guerra destruye la confianza. } \\
\text { Cuarta parte. }\end{array}$ & 7 \\
\hline 2003 & 23/02/2003 & 5262 & La doble moral. Primera parte. & 7 \\
\hline
\end{tabular}




\begin{tabular}{|c|c|c|c|c|}
\hline Año & FECHA & No. & $\begin{array}{c}\text { Nombre del artículo publicado en } \\
\text { Semanario Orientación }\end{array}$ & Págs. \\
\hline 2003 & 02/03/2003 & 5263 & $\begin{array}{l}\text { EL informe de amnistía internacional } \\
\text { (Segunda parte) }\end{array}$ & 7 \\
\hline 2003 & 09/03/2003 & 5264 & $\begin{array}{l}41 \text { Premios Nobel de EE.UU. opuestos a } \\
\text { la guerra (Tercera parte) }\end{array}$ & 7 \\
\hline 2003 & 16/03/2003 & 5265 & $\begin{array}{l}\text { "ONU no está preparada para crisis } \\
\text { humanitaria" (Cuarta parte) }\end{array}$ & 7 \\
\hline 2003 & 23/03/2003 & 5266 & $\begin{array}{l}\text { "No codiciarás los bienes de tu prójimo" } \\
\text { (Quinta parte) }\end{array}$ & 12 \\
\hline 2003 & $30 / 03 / 2003$ & 5267 & $\begin{array}{l}\text { El Papa se opone a la violencia ciega } \\
\text { (Sexta parte) }\end{array}$ & 7 \\
\hline 2003 & 06/04/2003 & 5268 & $\begin{array}{l}\text { Una guerra contra la humanidad } \\
\text { (Primera parte) }\end{array}$ & 7 \\
\hline 2003 & 13/04/2003 & 5269 & $\begin{array}{l}\text { En nombre de Dios y del Pueblo } \\
\text { (Segunda parte) }\end{array}$ & 11 \\
\hline 2003 & $27 / 04 / 2003$ & 5270 & $\begin{array}{l}\text { Carta abierta de Norman Birbaum } \\
\text { (Tercera parte) }\end{array}$ & 7 \\
\hline 2003 & 04/05/2003 & 5271 & $\begin{array}{l}\text { Irrespeto a las Naciones Unidas (Cuarta } \\
\text { parte) }\end{array}$ & 7 \\
\hline 2003 & 18/05/2003 & 5273 & $\begin{array}{l}\text { "Un mercado sin mercado" (Primera } \\
\text { parte) }\end{array}$ & 7 \\
\hline 2003 & $25 / 05 / 2003$ & 5274 & $\begin{array}{l}\text { "El desempleo estructural" (Segunda } \\
\text { parte) }\end{array}$ & 7 \\
\hline 2003 & 01/06/2003 & 5275 & $\begin{array}{l}\text { Crecimiento con desempleo (Tercera } \\
\text { parte) }\end{array}$ & 7 \\
\hline 2003 & 08/06/2003 & 5276 & $\begin{array}{l}\text { "Salvadoreños en busca de empleo" } \\
\text { (Cuarta parte) }\end{array}$ & 7 \\
\hline 2003 & $15 / 06 / 2003$ & 5277 & "Ya estamos decreciendo" (Última parte) & 7 \\
\hline 2003 & $29 / 06 / 2003$ & 5279 & Un paréntesis: ¿dónde están las armas? & 7 \\
\hline 2003 & 06/07/2003 & 5280 & Economía sin autocrítica (Primera parte) & 7 \\
\hline 2003 & $13 / 07 / 2003$ & 5281 & $\begin{array}{l}\text { "Desde el espejo retrovisor" (Segunda } \\
\text { parte) }\end{array}$ & 7 \\
\hline 2003 & $20 / 07 / 2003$ & 5282 & $\begin{array}{l}\text { "Hagamos nuestra autocrítica" (Tercera } \\
\text { parte) }\end{array}$ & 7 \\
\hline 2003 & $27 / 07 / 2003$ & 5283 & "1990: la década perdida" (Cuarta parte) & 7 \\
\hline 2003 & 03/08/2003 & 5284 & Construir el tejido social (Quinta parte) & 7 \\
\hline 2003 & $17 / 08 / 2003$ & 5285 & $\begin{array}{l}\text { Reforma de la Política Fiscal (Sexta } \\
\text { parte) }\end{array}$ & 5 \\
\hline 2003 & $31 / 08 / 2003$ & 5287 & "El muro de la discordia" (Primera parte) & 5 \\
\hline 2003 & 07/09/2003 & 5288 & $\begin{array}{l}\text { "Un muro contra la Corte Penal } \\
\text { Internacional" (Segunda parte) }\end{array}$ & 5 \\
\hline 2003 & $14 / 09 / 2003$ & 5289 & TLC "con leyes laborales" (Tercera parte) & 5 \\
\hline 2003 & $21 / 09 / 2003$ & 5290 & "Carta a la nación" (Cuarta parte) & 5 \\
\hline
\end{tabular}




\begin{tabular}{|c|c|c|c|c|}
\hline Año & FECHA & No. & $\begin{array}{c}\text { Nombre del artículo publicado en } \\
\text { Semanario Orientación }\end{array}$ & Págs. \\
\hline 2003 & $28 / 09 / 2003$ & 5291 & "La hora del cambio ha Ilegado" & 5 \\
\hline 2003 & 05/10/2003 & 5292 & Planes de desarrollo (Última parte) & 5 \\
\hline 2003 & $12 / 10 / 2003$ & 5293 & $\begin{array}{l}\text { La cumbre de Cancún: un mundo } \\
\text { unilateral (Primera parte) }\end{array}$ & 5 \\
\hline 2003 & $26 / 10 / 2003$ & 5295 & $\begin{array}{l}\text { La cumbre de Cancún: un mundo } \\
\text { unilateral (Segunda parte) }\end{array}$ & 5 \\
\hline 2003 & $02 / 11 / 2003$ & 5296 & $\begin{array}{l}\text { Manifestaciones en la OMC de Cancún } \\
\text { (Tercera parte) }\end{array}$ & 5 \\
\hline 2003 & 09/11/2003 & 5297 & $\begin{array}{l}\text { La novedad de Cancún: dos fuertes } \\
\text { bloques (Cuarta parte) }\end{array}$ & 5 \\
\hline 2003 & 16/11/2003 & 5298 & "Nadie da nada por nada" (Quinta parte) & 5 \\
\hline 2003 & $23 / 11 / 2003$ & 5299 & $\begin{array}{l}\text { Después de Cancún: ¿qué? (Última } \\
\text { parte) }\end{array}$ & 5 \\
\hline 2003 & 07/12/2003 & 5301 & "Un derecho de la paz" (Primera parte) & 5 \\
\hline 2003 & $14 / 12 / 2003$ & 5302 & $\begin{array}{l}\text { "El derecho de injerencia" (Segunda } \\
\text { parte) }\end{array}$ & 5 \\
\hline 2003 & $21 / 12 / 2003$ & 5303 & $\begin{array}{l}\text { El Consejo de Seguridad de las Naciones } \\
\text { Unidas (Tercera parte) }\end{array}$ & 5 \\
\hline 2003 & 28/12/2003 & 5304 & $\begin{array}{l}\text { El Consejo de Seguridad y la Corte Penal } \\
\text { Internacional (Cuarta parte) }\end{array}$ & 14 \\
\hline 2004 & $11 / 01 / 2004$ & 5305 & $\begin{array}{l}\text { Saldam Hussein ¿era una amenaza para } \\
\text { Estados Unidos? (Quinta parte) }\end{array}$ & 5 \\
\hline 2004 & 18/01/2004 & 5306 & $\begin{array}{l}\text { La doctrina de la ONU sobre derecho } \\
\text { internacional (Sexta parte) }\end{array}$ & 5 \\
\hline 2004 & $25 / 01 / 2004$ & 5307 & $\begin{array}{l}\text { "La confusa resolución del Consejo de } \\
\text { Seguridad" (Última parte) }\end{array}$ & 5 \\
\hline 2004 & $01 / 02 / 2004$ & 5308 & Dos novedades del mensaje (I parte) & 5 \\
\hline 2004 & 08/02/2004 & 5309 & $\begin{array}{l}\text { Causas del terrorismo y políticas } \\
\text { antiterrorismo (Il entrega) }\end{array}$ & 5 \\
\hline 2004 & $15 / 02 / 2004$ & 5310 & $\begin{array}{l}\text { "Las amenazas duras y las amenazas } \\
\text { blandas" (III parte) }\end{array}$ & 5 \\
\hline 2004 & $22 / 02 / 2004$ & 5311 & $\begin{array}{l}\text { "Un nuevo ordenamiento internacional" } \\
\text { (IV parte) }\end{array}$ & 5 \\
\hline 2004 & $29 / 02 / 2004$ & 5312 & $\begin{array}{l}\text { La ONU y la observancia del derecho } \\
\text { (V parte) }\end{array}$ & 8 \\
\hline 2004 & 07/03/2004 & 5313 & $\begin{array}{l}\text { La oportunidad del mensaje: ¿a quiénes } \\
\text { habla el Papa? (VI) }\end{array}$ & 5 \\
\hline 2004 & $28 / 03 / 2004$ & 5316 & $\begin{array}{l}\text { "El eje del mal": la pobreza, el SIDA y la } \\
\text { guerra (I) }\end{array}$ & 5 \\
\hline 2004 & 04/04/2004 & 5317 & $\begin{array}{l}\text { "Las castas, los intocables y las tribus" } \\
\text { (II) }\end{array}$ & 5 \\
\hline 2004 & $18 / 04 / 2004$ & 5318 & $\begin{array}{l}\text { "Los derechos de la mujer y la Corte } \\
\text { Penal Internacional" (III) }\end{array}$ & 5 \\
\hline 2004 & $25 / 04 / 2004$ & 5319 & Cuestionamiento de la globalización (IV) & 7 \\
\hline
\end{tabular}




\begin{tabular}{|c|c|c|c|c|}
\hline Año & FECHA & No. & $\begin{array}{c}\text { Nombre del artículo publicado en } \\
\text { Semanario Orientación }\end{array}$ & Págs. \\
\hline 2004 & 02/05/2004 & 5320 & $\begin{array}{l}\text { En el foro de Bombay se analiza la } \\
\text { globalización }(\mathrm{V})\end{array}$ & 7 \\
\hline 2004 & 09/05/2004 & 5321 & $\begin{array}{l}\text { En Bombay se cuestiona la globalización } \\
\text { (Final) }\end{array}$ & 7 \\
\hline 2004 & $13 / 06 / 2004$ & 5326 & Un acto de vasallaje (I parte) & 7 \\
\hline 2004 & $20 / 06 / 2004$ & 5327 & $\begin{array}{l}\text { "Mano dura dentro y mano blanda fuera" } \\
\text { (Il parte) }\end{array}$ & 7 \\
\hline 2004 & $27 / 06 / 2004$ & 5328 & En busca del eslabón (I parte) & 7 \\
\hline 2004 & 04/07/2004 & 5329 & $\begin{array}{l}\text { Las expectativas optimistas; el resto anda } \\
\text { mal. }\end{array}$ & 7 \\
\hline 2004 & $11 / 07 / 2004$ & 5330 & Un modelo sin autocrítica (Parte final) & 7 \\
\hline 2004 & $18 / 07 / 2004$ & 5331 & un plan de austeridad (Primera parte) & 7 \\
\hline 2004 & $25 / 07 / 2004$ & 5332 & $\begin{array}{l}\text { El TPS de Estados Unidos (Segunda } \\
\text { parte) }\end{array}$ & 7 \\
\hline 2004 & 01/08/2004 & 5333 & $\begin{array}{l}\text { "No tenemos más opción que un TLC" } \\
\text { (Tercera Parte) }\end{array}$ & 7 \\
\hline 2004 & $22 / 08 / 2004$ & 5335 & $\begin{array}{l}\text { "Los desafíos económicos y sociales del } \\
\text { nuevo gobierno" (Cuarta Parte) }\end{array}$ & 7 \\
\hline 2004 & $29 / 08 / 2004$ & 5336 & $\begin{array}{l}\text { "Los desafíos del nuevo gobierno" } \\
\text { (Quinta Parte) }\end{array}$ & 7 \\
\hline 2004 & 05/09/2004 & 5337 & $\begin{array}{l}\text { La pobreza en un contexto de elevada } \\
\text { desigualdad (Última entrega) }\end{array}$ & 7 \\
\hline 2004 & $12 / 09 / 2004$ & 5338 & $\begin{array}{l}\text { Nuevo acuerdo-marco de la } \\
\text { Organización Mundial del Comercio } \\
\text { (Primera parte) }\end{array}$ & 7 \\
\hline 2004 & 19/09/2004 & 5339 & $\begin{array}{l}\text { Nuevo acuerdo-marco de la } \\
\text { Organización Mundial del Comercio } \\
\text { (Segunda parte) }\end{array}$ & 7 \\
\hline 2004 & $26 / 09 / 2004$ & 5340 & $\begin{array}{l}\text { Brasil enfrenta a Estados Unidos en la } \\
\text { negociación del ALCA (Tercera parte) }\end{array}$ & 7 \\
\hline 2004 & 03/10/2004 & 5341 & $\begin{array}{l}\text { La voz de las Iglesias ante las } \\
\text { negociaciones del ALCA (Cuarta parte) }\end{array}$ & 7 \\
\hline 2004 & 10/10/2004 & 5342 & $\begin{array}{l}\text { Los puntos principales del acuerdo- } \\
\text { marco de Ginebra (Quinta parte) }\end{array}$ & 7 \\
\hline 2004 & $17 / 10 / 2004$ & 5343 & $\begin{array}{l}\text { ¿Qué dicen los actores del acuerdo- } \\
\text { marco de la OMC en Ginebra? (Sexta } \\
\text { parte) }\end{array}$ & 7 \\
\hline 2004 & 24/10/2004 & 5344 & ¿Es nuestra Arca de la Alianza? (Final) & 7 \\
\hline 2004 & $07 / 11 / 2004$ & 5346 & $\begin{array}{l}\text { Un fantasma recorre el mundo... } \\
\text { (Primera parte) }\end{array}$ & 7 \\
\hline 2004 & $14 / 11 / 2004$ & 5347 & $\begin{array}{l}\text { El pacto Moscú-Washington (Segunda } \\
\text { parte) }\end{array}$ & 7 \\
\hline 2004 & $21 / 11 / 2004$ & 5348 & $\begin{array}{l}\text { Juan Pablo II: "Educar para la paz" } \\
\text { (Tercera parte) }\end{array}$ & 7 \\
\hline
\end{tabular}




\begin{tabular}{|c|c|c|c|c|}
\hline Año & FECHA & No. & $\begin{array}{l}\text { Nombre del artículo publicado en } \\
\text { Semanario Orientación }\end{array}$ & Págs. \\
\hline 2004 & $28 / 11 / 2004$ & 5349 & $\begin{array}{l}\text { El diálogo de civilizaciones (Cuarta } \\
\text { parte) }\end{array}$ & 7 \\
\hline 2004 & $05 / 12 / 2004$ & 5350 & El impenitente Bush (Quinta parte) & 7 \\
\hline 2004 & $12 / 12 / 2004$ & 5351 & $\begin{array}{l}\text { "El derecho de la fuerza y la fuerza del } \\
\text { derecho" (Última parte) }\end{array}$ & 7 \\
\hline 2004 & $19 / 12 / 2004$ & 5352 & $\begin{array}{l}\text { "La Iglesia pide examinar TLC" (Primera } \\
\text { parte) }\end{array}$ & 7 \\
\hline 2005 & 09/01/2005 & 5354 & $\begin{array}{l}\text { Antes del TLC un poco de autocrítica } \\
\text { (Segunda parte) }\end{array}$ & 7 \\
\hline 2005 & $16 / 01 / 2005$ & 5355 & 2004, año de estanflación (Tercera parte) & 7 \\
\hline 2005 & $23 / 01 / 2005$ & 5356 & $\begin{array}{l}\text { El "Consenso Salvadoreño" (Cuarta } \\
\text { parte) }\end{array}$ & 5 \\
\hline 2005 & $30 / 01 / 2005$ & 5357 & $\begin{array}{l}\text { ¿Qué es el bien y quién es el mal? } \\
\text { (Primera parte) }\end{array}$ & 7 \\
\hline 2005 & 06/02/2005 & 5358 & $\begin{array}{l}\text { "El bien común y el destino universal de } \\
\text { los bienes" (Segunda parte) }\end{array}$ & 7 \\
\hline 2005 & $13 / 02 / 2005$ & 5359 & $\begin{array}{l}\text { Fin de siglo: "la paz violenta" (Tercera } \\
\text { parte) }\end{array}$ & 7 \\
\hline 2005 & $20 / 02 / 2005$ & 5360 & $\begin{array}{l}\text { La Organización de las Naciones Unidas } \\
\text { como hacedora de paz (Cuarta parte) }\end{array}$ & 5 \\
\hline 2005 & $27 / 02 / 2005$ & 5361 & $\begin{array}{l}\text { El bien y el mal desde la Declaración del } \\
\text { Milenio (Quinta parte) }\end{array}$ & 7 \\
\hline 2005 & 06/03/2005 & 5362 & $\begin{array}{l}\text { Reforma y contrarreforma de las } \\
\text { Naciones Unidas (Sexta parte) }\end{array}$ & 7 \\
\hline 2005 & $13 / 03 / 2005$ & 5363 & $\begin{array}{l}\text { Las amenazas duras y las amenazas } \\
\text { blandas (Séptima parte) }\end{array}$ & 7 \\
\hline 2005 & $17 / 04 / 2005$ & 5367 & $\begin{array}{l}\text { El foro de Davos con sabor a Porto Alegre } \\
\text { (Primera parte) }\end{array}$ & 5 \\
\hline 2005 & $24 / 04 / 2005$ & 5368 & $\begin{array}{l}\text { La lucha contra la extrema pobreza } \\
\text { (Segunda parte) }\end{array}$ & 7 \\
\hline 2005 & $01 / 05 / 2005$ & 5369 & $\begin{array}{l}\text { El Foro social en Porto Alegre (Tercera } \\
\text { parte) }\end{array}$ & 7 \\
\hline 2005 & 08/05/2005 & 5370 & $\begin{array}{l}\text { Algunas propuestas de Porto Alegre } 2005 \\
\text { (Cuarta parte) }\end{array}$ & 7 \\
\hline 2005 & $15 / 05 / 2005$ & 5371 & $\begin{array}{l}\text { "Bush II: misionero de la libertad en el } \\
\text { mundo" (Quinta parte) }\end{array}$ & 7 \\
\hline 2005 & $22 / 05 / 2005$ & 5372 & $\begin{array}{l}\text { "De Iraq a Irán y tiro porque me toca" } \\
\text { (Sexta parte) }\end{array}$ & 7 \\
\hline 2005 & 29/05/2005 & 5373 & $\begin{array}{l}\text { "Bush promete bajar los precios de la } \\
\text { gasolina" (Primera parte) }\end{array}$ & 7 \\
\hline 2005 & 05/06/2005 & 5374 & $\begin{array}{l}\text { Breve historia de la crisis energética } \\
\text { (Segunda parte) }\end{array}$ & 7 \\
\hline 2005 & 12/06/2005 & 5375 & $\begin{array}{l}\text { La propuesta de "energías limpias" en } \\
\text { Johannesburgo, } 2002 \text { (Tercera parte) }\end{array}$ & 7 \\
\hline 2005 & 19/06/2005 & 5376 & $\begin{array}{l}\text { Del petróleo a la energía nuclear (Cuarta } \\
\text { parte) }\end{array}$ & 7 \\
\hline
\end{tabular}




\begin{tabular}{|c|c|c|c|c|}
\hline Año & FECHA & No. & $\begin{array}{l}\text { Nombre del artículo publicado en } \\
\text { Semanario Orientación }\end{array}$ & Págs. \\
\hline 2005 & 26/06/2005 & 5377 & Los residuos nucleares (Quinta parte) & 7 \\
\hline 2005 & 03/07/2005 & 5378 & $\begin{array}{l}\text { La mejor solución debe venir de } \\
\text { Naciones Unidas (Última parte) }\end{array}$ & 7 \\
\hline 2005 & $31 / 07 / 2005$ & 5382 & Antecedentes históricos (Primera parte) & 7 \\
\hline 2005 & 21/08/2005 & 5384 & $\begin{array}{l}\text { "África es un continente rico; los } \\
\text { africanos somos pobres" (Segunda parte) }\end{array}$ & 7 \\
\hline 2005 & 28/08/2005 & 5385 & $\begin{array}{l}\text { Los compromisos del G-8 "a la sombra } \\
\text { del terrorismo" (Tercera parte) }\end{array}$ & 7 \\
\hline 2005 & 04/09/2005 & 5386 & $\begin{array}{l}\text { La reducción de las subvenciones } \\
\text { agrícolas (Cuarta parte) }\end{array}$ & 7 \\
\hline 2005 & $11 / 09 / 2005$ & 5387 & $\begin{array}{l}\text { ¿Un compromiso moral sin caer en el } \\
\text { pánico? (Quinta parte) }\end{array}$ & 7 \\
\hline 2005 & 18/09/2005 & 5388 & $\begin{array}{l}\text { ¿Por qué solo el terror del Norte dicen } \\
\text { que es obra del terrorismo? (Última } \\
\text { parte) }\end{array}$ & 7 \\
\hline 2005 & 25/09/2005 & 5389 & El enigma nuclear (Primera parte) & 7 \\
\hline 2005 & 02/10/2005 & 5390 & $\begin{array}{l}\text { Un legado para la humanidad (Segunda } \\
\text { parte) }\end{array}$ & 7 \\
\hline 2005 & 09/10/2005 & 5391 & $\begin{array}{l}\text { El peligro de la proliferación nuclear } \\
\text { (Tercera parte) }\end{array}$ & 7 \\
\hline 2005 & 16/10/2005 & 5392 & $\begin{array}{l}\text { Las nuevas armas nucleares y el futuro de } \\
\text { la humanidad (Cuarta parte) }\end{array}$ & 7 \\
\hline 2005 & 23/10/2005 & 5393 & $\begin{array}{l}\text { "De Irak a Irán y tiro porque me toca" } \\
\text { (Quinta parte) }\end{array}$ & 7 \\
\hline 2005 & $30 / 10 / 2005$ & 5394 & $\begin{array}{l}\text { Irán, el chivo expiatorio nuclear (Última } \\
\text { parte) }\end{array}$ & 7 \\
\hline 2005 & 06/11/2005 & 5395 & $\begin{array}{l}\text { ¿Por qué nos han decepcionado? } \\
\text { (Primera parte) }\end{array}$ & 7 \\
\hline 2005 & $13 / 11 / 2005$ & 5396 & "Querida ONU" (Segunda parte) & 7 \\
\hline 2005 & 20/11/2005 & 5397 & $\begin{array}{l}\text { Cardenal Angelo Sodano: "Los pobres } \\
\text { no pueden esperar" (Tercera parte) }\end{array}$ & 7 \\
\hline 2005 & $27 / 11 / 2005$ & 5398 & El punto de partida (Cuarta parte) & 7 \\
\hline 2005 & 04/12/2005 & 5399 & $\begin{array}{l}\text { El Consejo de Seguridad y la Corte Penal } \\
\text { Internacional (Quinta parte) }\end{array}$ & 7 \\
\hline 2005 & $11 / 12 / 2005$ & 5400 & $\begin{array}{l}\text { El Concejo de Seguridad y "el muro de } \\
\text { Cisjordania" (Sexta parte) }\end{array}$ & 7 \\
\hline 2005 & 18/12/2005 & 5401 & $\begin{array}{l}\text { ¿lmprovisación y demasiados puntos de } \\
\text { agenda? (Séptima parte) }\end{array}$ & 7 \\
\hline 2005 & 25/12/2005 & 5402 & $\begin{array}{l}\text { "Las amenazas duras y las amenazas } \\
\text { blandas" (Ultima parte) }\end{array}$ & 6 \\
\hline 2006 & 08/01/2006 & 5403 & $\begin{array}{l}\text { Mar de Plata, OMC en Hong Kong y } \\
\text { nuestro TLC (Primera parte) }\end{array}$ & 7 \\
\hline 2006 & $15 / 01 / 2006$ & 5404 & $\begin{array}{l}\text { Los ocho grupos de "Negociación" en } \\
\text { Doha y en ALCA-Miami (Segunda parte) }\end{array}$ & 7 \\
\hline 2006 & $22 / 01 / 2006$ & 5405 & La voz de las Iglesias (Tercera parte) & 7 \\
\hline
\end{tabular}




\begin{tabular}{|c|c|c|c|c|}
\hline Año & FECHA & No. & $\begin{array}{c}\text { Nombre del artículo publicado en } \\
\text { Semanario Orientación }\end{array}$ & Págs. \\
\hline 2006 & 29/01/2006 & 5406 & $\begin{array}{l}\text { Consternación, decepción y traición en } \\
\text { la OMC de Hong Kong (Ultima parte) }\end{array}$ & 7 \\
\hline 2006 & 05/02/2006 & 5407 & $\begin{array}{l}\text { Sin verdad no hay paz ni justicia mundial } \\
\text { (Primera parte) }\end{array}$ & 7 \\
\hline 2006 & $12 / 02 / 2006$ & 5408 & $\begin{array}{l}\text { Condena de la tortura como estrategia } \\
\text { antiterrorista (Segunda parte) }\end{array}$ & 7 \\
\hline 2006 & 19/02/2006 & 5409 & $\begin{array}{l}\text { Condena de la tortura como estrategia } \\
\text { antiterrorista (Tercera parte) }\end{array}$ & 7 \\
\hline 2006 & $26 / 02 / 2006$ & 5410 & $\begin{array}{l}\text { Los terrorismos en el nuevo milenio } \\
\text { (Cuarta parte) }\end{array}$ & 7 \\
\hline 2006 & 05/03/2006 & 5411 & $\begin{array}{l}\text { Terrorismo: un tema central del mensaje } \\
\text { papal (Quinta parte) }\end{array}$ & 7 \\
\hline 2006 & 12/03/2006 & 5412 & $\begin{array}{l}\text { Los terrorismos en el nuevo milenio: Un } \\
\text { premio Nóbel de la Paz (Sexta parte) }\end{array}$ & 7 \\
\hline 2006 & 19/03/2006 & 5413 & $\begin{array}{l}\text { El Derecho Internacional Humanitario y } \\
\text { el papel de la ONU (Séptima parte) }\end{array}$ & 7 \\
\hline 2006 & 26/03/2006 & 5414 & $\begin{array}{l}\text { La ley del más fuerte en las Naciones } \\
\text { Unidas (Octava parte) }\end{array}$ & 7 \\
\hline 2006 & 02/04/2006 & 5415 & $\begin{array}{l}\text { Mijail Gorbachov: Nuevas relaciones } \\
\text { Internacionales (Novena parte) }\end{array}$ & 7 \\
\hline 2006 & 09/04/2006 & 5416 & $\begin{array}{l}\text { Consejo de Seguridad y Corte Penal } \\
\text { Internacional (Decima parte) }\end{array}$ & 7 \\
\hline 2006 & $23 / 04 / 2006$ & 5417 & La amenaza nuclear (Undecima parte) & 11 \\
\hline 2006 & $30 / 04 / 2006$ & 5418 & La amenaza nuclear (Duodecima parte) & 14 \\
\hline 2006 & 07/05/2006 & 5419 & $\begin{array}{l}\text { "La verdad" del Libre comercio y de la } \\
\text { OMC (Decimo tercera parte) }\end{array}$ & 13 \\
\hline 2006 & 14/05/2006 & 5420 & $\begin{array}{l}\text { La verdad del libre comercio (Ultima } \\
\text { parte) }\end{array}$ & 7 \\
\hline 2006 & $21 / 05 / 2006$ & 5421 & $\begin{array}{l}\text { El compromiso de los jefes de Estado } \\
\text { (Primera parte) }\end{array}$ & 7 \\
\hline 2006 & 28/05/2006 & 5422 & $\begin{array}{l}\text { Los Objetivos del Milenio (Segunda } \\
\text { parte) }\end{array}$ & 7 \\
\hline 2006 & 04/06/2006 & 5423 & $\begin{array}{l}\text { Antecedentes de los objetivos del milenio } \\
\text { (Tercera parte) }\end{array}$ & 7 \\
\hline 2006 & 11/06/2006 & 5424 & $\begin{array}{l}\text { Antecedente: las cumbres de Naciones } \\
\text { Unidas en los noventa (Cuarta parte) }\end{array}$ & 11 \\
\hline 2006 & 18/06/2006 & 5425 & $\begin{array}{l}\text { Antecedente: las cumbres de Naciones } \\
\text { Unidas en los noventa (Quinta parte) }\end{array}$ & 7 \\
\hline 2006 & 25/06/2006 & 5426 & $\begin{array}{l}\text { La globalización hace difícil la } \\
\text { globalización (Sexta parte) }\end{array}$ & 7 \\
\hline 2006 & 02/07/2006 & 5427 & $\begin{array}{l}\text { "Consenso de Monterrey": Financiar el } \\
\text { Desarrollo (Séptima parte) }\end{array}$ & 7 \\
\hline 2006 & 09/07/2006 & 5428 & $\begin{array}{l}\text { La Cumbre de Monterrey: el alivio de la } \\
\text { pobreza (Octava parte) }\end{array}$ & 7 \\
\hline 2006 & 16/07/2006 & 5429 & $\begin{array}{l}\text { La Corrupción, el gran obstáculo al alivio } \\
\text { de la pobreza (Novena parte) }\end{array}$ & 7 \\
\hline
\end{tabular}




\begin{tabular}{|c|c|c|c|c|}
\hline Año & FECHA & No. & $\begin{array}{c}\text { Nombre del artículo publicado en } \\
\text { Semanario Orientación }\end{array}$ & Págs. \\
\hline 2006 & 23/07/2006 & 5430 & $\begin{array}{l}\text { "El peor genocidio que la humanidad ha } \\
\text { conocido" (Décima parte) }\end{array}$ & 7 \\
\hline 2006 & $30 / 07 / 2006$ & 5431 & $\begin{array}{l}\text { El Área de Libre Comercio de las } \\
\text { Américas (ALCA) (Décima primera parte) }\end{array}$ & 7 \\
\hline 2006 & 13/08/2006 & 5432 & $\begin{array}{l}\text { El respeto de la naturaleza (Duodécima } \\
\text { parte) }\end{array}$ & 7 \\
\hline 2006 & 20/08/2006 & 5433 & $\begin{array}{l}\text { Terrorismo hace inviables los Objetivos } \\
\text { del Milenio (Décimo tercera parte) }\end{array}$ & 7 \\
\hline 2006 & 27/08/2006 & 5434 & $\begin{array}{l}\text { Se corre el telón de la verdad y de la } \\
\text { mentira (Décima cuarta parte) }\end{array}$ & 7 \\
\hline 2006 & 03/09/2006 & 5435 & $\begin{array}{l}\text { "La nueva estrategia de Seguridad } \\
\text { Nacional (USA)" (Décima quinta parte) }\end{array}$ & 7 \\
\hline 2006 & 10/09/2006 & 5436 & $\begin{array}{l}\text { Mensaje pascual de Benedicto XVI } \\
\text { (Primera parte) }\end{array}$ & 7 \\
\hline 2006 & 17/09/2006 & 5437 & $\begin{array}{l}\text { "Principales problemas estructurales de } \\
\text { El Salvador" (Segunda parte) }\end{array}$ & 7 \\
\hline 2006 & 24/09/2006 & 5438 & $\begin{array}{l}\text { "Principales problemas estructurales de } \\
\text { El Salvador". II (Tercera parte) }\end{array}$ & 7 \\
\hline 2006 & 01/10/2006 & 5439 & $\begin{array}{l}\text { "La moneda, el álgebra de la actividad } \\
\text { humana" (Cuarta parte) }\end{array}$ & 7 \\
\hline 2006 & 08/10/2006 & 5440 & $\begin{array}{l}\text { "La otra crisis". Discurso de James } \\
\text { Wolfenshon (B.M.) } \quad \text { (Quinta parte) }\end{array}$ & 7 \\
\hline 2006 & 15/10/2006 & 5441 & $\begin{array}{l}\text { La lucha contra la pobreza en el Foro } \\
\text { Económico de Davos } 2005 \text { (Sexta parte) }\end{array}$ & 7 \\
\hline 2006 & $22 / 10 / 2006$ & 5442 & $\begin{array}{l}\text { Paul Wolfowitz lanza un plan } \\
\text { anticorrupción (Séptima parte) }\end{array}$ & 7 \\
\hline 2006 & 29/10/2006 & 5443 & $\begin{array}{l}\text { Nuevo fracaso de la Organización } \\
\text { Mundial del Comercio (Octava parte) }\end{array}$ & 7 \\
\hline 2006 & 05/11/2006 & 5444 & $\begin{array}{l}\text { El costo social del capitalismo en China } \\
\text { (Novena parte) }\end{array}$ & 7 \\
\hline 2006 & $12 / 11 / 2006$ & 5445 & $\begin{array}{l}\text { "El Tribunal Supremo de EE.UU. invalida } \\
\text { los tribunales militares de Guantánamo" } \\
\text { (Última parte) }\end{array}$ & 7 \\
\hline 2006 & 19/11/2006 & 5446 & $\begin{array}{l}\text { ¿Quién es Mijail Gorbachov? (Primera } \\
\text { parte) }\end{array}$ & 7 \\
\hline 2006 & $26 / 11 / 2006$ & 5447 & $\begin{array}{l}\text { Mijail Gorbachov en su infancia } \\
\text { (Segunda parte) }\end{array}$ & 7 \\
\hline 2006 & 03/12/2006 & 5448 & $\begin{array}{l}\text { Degradación ambiental, Chernobil y el } \\
\text { credo antinuclear (Tercera parte) }\end{array}$ & 7 \\
\hline 2006 & 10/12/2006 & 5449 & $\begin{array}{l}\text { Mijail Gorbachov y su idea de } \\
\text { Socialismo (Cuarta parte) }\end{array}$ & 7 \\
\hline 2006 & 17/12/2006 & 5450 & $\begin{array}{l}\text { "Nuevo desorden mundial" (Cuarta } \\
\text { parte) }\end{array}$ & 7 \\
\hline 2006 & 24/12/2006 & 5451 & Una crisis económica (Sexta parte) & 7 \\
\hline
\end{tabular}


PROCESO

\begin{tabular}{|c|c|c|c|c|}
\hline Año & FECHA & No. & Nombre del artículo & Págs. \\
\hline 2000 & Nov-22 & $\begin{array}{l}\text { Año } 21 \\
\text { No. } 928\end{array}$ & $\begin{array}{l}\text { "Caminando sobre bases sólidas". } \\
\text { Discurso presidencial en FELABAN }\end{array}$ & $6-8$ \\
\hline 2001 & Ago-23 & $\begin{array}{l}\text { Año 22, } \\
\text { No. } 964\end{array}$ & $\begin{array}{l}\text { Los europeos desaprueban la política } \\
\text { exterior de G.W. Bush }\end{array}$ & $8-9$ \\
\hline 2005 & May-04 & $\begin{array}{l}\text { Año } 25, \\
\text { No. } 1143\end{array}$ & $\begin{array}{l}\text { La "crisis energética" ya tiene una } \\
\text { respuesta }\end{array}$ & $10-11$ \\
\hline 2005 & May-18 & $\begin{array}{l}\text { Año } 25, \text { No. } \\
1145\end{array}$ & $\begin{array}{l}\text { Los sectores medios, tradicionales } \\
\text { (Editorial) }\end{array}$ & $2-3$ \\
\hline
\end{tabular}

